$\frac{12}{1.13 .928 \delta(1) ~}$

$\frac{\text { PNL-7871 }}{\text { UC-731 }}$

\title{
Savannah River Restart \\ Peer Evaluation Program \\ Final Examination Report
}
M. P. Morgan
D. G. Draper

December 1991

Prepared for the U.S. Department of Energy under Contract DE-AC06-76RLO 1830

Pacific Northwest Laboratory Operated for the U.S. Department of Energy by Battelle Memorial Institute 


\title{
DISC!AIMER
}

This report was prepared as an account of work sponsored by an agency of the United States Government. Neither the United States Government nor any agency thereof, nor Battelle Memorial Institute. nor any of their employees, makes any warranty, expressed or implied, or assumes any legal liability or responsibility for the accuracy, completeness, or usefulness of any information, apparatus, product, or process disclosed, or represents that its use would not infringe privately owned rights. Reference herein to any specific commercial product. process, or service by trade name, trademark, manufacturer, or otherwise does not necessarily constitute or imply its endorsement, recommendation, or favoring by the Uritted States Government or any agency thereof, or Baltelle Memorial Institute. The views and opinions of authors expressed herein do not necessarily state or reflect those of the Unired States Government or any agency thereof.

\author{
PACIFIC NORTHWEST LABORATORY \\ operated by \\ BATTELLE MEMORIAL INSTITUTE \\ for the \\ UNITED STATES DEPARTMENT OF ENERGY \\ under Contract DE-AC06-76RLO 1830
}

Printed in the United States of America

Available to DOE and DOE contractors from the

Office of Scientific and Technical Information, P.O. Box 62, Oak Ridge, IN 37831; prices available from (615) 576-8401. FTS 626-8401.

Available to the public from the National Technical Information Service, U.S. Department of Commerce, 5285 Port Royal Rd., Springfield, VA 22161. 
PNL- - 7871

DE92 004849

SAVANNAH RIVER RESTART

PEER EVALUATION PROGRAM

FINAL EXAMINATION REPORT

M. P. Morgan

D. G. Draper

December 1991

Prepared for

the U. S. Department of Energy

under Contract DE-ACO6-76RLO 1830

Pacific Northwest Laboratory

Richland, Washington 99352 


\section{SUMMARY}

During the period of August 13, 1990 through September 6, 1991 the Savannah River Peer Evaluation Program was administered during three distinct phases to 73 certified Central Control Room Operators, Central Control Room Supervisors, and Shift Technical Engineers assigned to the $K$ Reactor, on the Savannah River Site (SRS). This program was conceived and developed by the Department of Energy (DOE) and it's implementation satisfies recommendations made by the Defense Nuclear Facilities Safety Board.

The examination process was administered by Westinghouse-Savannah River Company (WSRC) and evaluated in parallel by Nuclear Regulatory Commission (NRC) certified examiners contracted by the Department of Energy. A detailed discussion of the examination development and administration methodology is provided in Appendices $A$ and $B$.

The examination results were as follows; of the 73 individuals who participated in one or more phases of the examination process, 12 supervisors, 28 operators and seven Shift Technical Engineers (STES) comprising five crews successfully completed Phase III testing. A detailed report of examination results is provided in Section 2 .

A post-examination data base was established to identify specific areas of strength and weakness. The results of the data base analysis are provided in Section 3.

General observations made by the DOE evaluation team are provided in Section 4. Specific areas noted for continuing improvement were:

- Understanding of electrical systems and theory,

- Understanding of neutron flux monitoring equipment,

- Procedural adequacy and procedural compliance,

- Crew communications and command/control, and

- Performance of routine control room calculations.

The examination process lised at the Savannah River Site is valid in both process and content. It is comparable to and consistent with a Nuclear 
Regulatory Commission (NRC) requalification examination used for relicensing commercial nuclear utility operators.

Conclusions drawn by the DOE Evaluators from the Peer Evaluation Program are as follows:

- The previous certification process had failed to adequately screen candidates. Although many individuals were observed who would be above average in the commercial industry, unsatisfactory individuals had obtained certification as well. A high failure rate throughout the testing process demonstrated a need for the development of a comprehensive evaluation program, such as the Peer Evaluation Program,

- The absence of symptom based Emergency Operating Procedures detracted from the general command and control skills observed of the supervisors,

- The intensity of control room alarms detracted from the crews ability to function effectively,

- Supervisors demonstrated a lack of sensitivity to the implications associated with overclassifying Emergency Action Levels (EALs),

- The general level of training and performance demonstrated by operating personnel, both individually and as members of crews, significantly improved through the three phases of testing,

- Generic and individual weaknesses have been idéntified and are being remediated, and

- Operating personnel have accepted their redefined responsibilities and seem receptive to the new approach to Conduct of Operations being implemented at Savannah River Site.

It should be noted that operations personnel at Savannah River have not completed all training on reactor fundamentals and were not evaluated in that area during any phase of the Peer Evaluation Program. WSRC training has committed to complete fundamentals training within two years and testing will be done at that time. Fundamentals training will enhance sperator efficiency and will improve performance beyond the presently achieved safe standard. 


\section{CONTENTS}

SUMMARY . . . . . . . . . . . . . . . . . . . . . . . . . i i

1.0 PROGRAM OBJECTIVE/OVERVIEW . . . . . . . . . . . . . . . . . 1

2.0 SUMMARY OF EXAMINATION RESULTS . . . . . . . . . . . . . . . . . 3

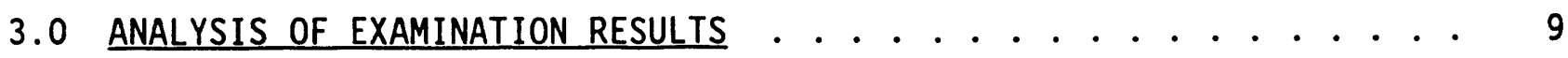

4.0 GENERAL OBSERVATIONS . . . . . . . . . . . . . . . . . . . . . . 21

5.0 ONGOING SUPPORT ACTIVITIES . . . . . . . . . . . . . . . . . . . 25

APPENDIX A . . . . . . . . . . . . . . . . . . . . . . . . A.1

APPENDIX B . . . . . . . . . . . . . . . . . . . . . . . B. 1 


\section{TABLES}

TABLE 2.1 Overall Phase I and II Examination Results Summary . . . . . 7

TABLE 2.2 Overall Phase III Examination Results Summary . . . . . . 8

TABLE 3.1 Phase III Written Examination Summary of Generic Weaknesses . 15

TABLE 3.2 Phase III Written Examination Summary of Generic Strengths . . 15

TABLE 3.3 System Analysis for Certified CCROs . . . . . . . . . . . 16

TABLE 3.4 Phase III JPMs with Average Success Rate of $<80 \%$. . . . . . 17

TABLE 3.5 Phase III JPMs with Oral Question Average Success Rate of $<80 \%$..................... 17

TABLE 3.6 Crew Competency Analysis by Phase . . . . . . . . . . 18

IABLE 3.7 Individual Competency Analysis for Phase III . . . . . . . . 19 


\subsection{PROGRAM OBJECTIVE/OVERVIEW}

The objective of the Peer Evaluation program is to determine the readiness of the certified Central Control Room Supervisors (CCRSs) and Central Control Room Operators (CCROs) at the $K$ Reactor, located on the Savannah River Site (SRS), to safely conduct restart and power operations following an extended shutdown. The Peer Evaluation program was conceived and developed by the Department of Energy (DOE) at Savannah River Site. This decision was formally announced in a DOE response to recommendations from the Defense Nuclear Facilities Safety Board (DNFSB). The specific response states:

"Prior to restart, DOE and Westinghouse will jointly conduct comprehensive evaluations of certified supervisors and senior reactor operators to ensure that they can demonstrate the appropriate knowledge and abilities required for safe restart. The examinations are intended to be conducted in August, 1990 in order to allow for proper development of the examinations and for completion of recent enhancements to the training program."

The examinations were conducted over a year's period in three distinct phases. The phase I examinations were initial examinations of five operating crews conducted from August 13 through September 14, 1990. A total of 48 operators participated in this examination process. The phase II examinations were conducted from 0ctober 22 through November 21, 1990. This phase was a retest of operators and crews who had failed the phase I examination. A total of 29 operators participated in the phase II examination process. The phase III examination comprised a reexamination of all operators required to support reactor restart. The reasons that a complete reexamination was deemed necessary were:

- The original testing criteria was based on a limited set of knowledge and abilities as defined in the SRS Knowledges/Abilities (K/A) Catalog. With the delay in reactor restart, it was determined that additional training time was available to allow expansion of the testing boundaries to include all knowledge and abilities in the K/A catalog,

- Upon completion of phase I and II testing, the DOE and SRS peer evaluators recommended significant changes to the examination 
process to improve their ability to reliably discriminate between safe/unsafe operators and to parallel revisions in the examination process used by the Nuclear Regulatory Commission (NRC), and

- In 1 ine with the changes above, a review of the written examination process was conducted by the Department of Energy, Westinghouse and the Defense Nuclear Facility Safety Board. The results of the review indicated an expanded written examination was required to include knowledge elements that should be committed to memory by a safe operator and expand question format to include essay and short answer styles in addition to the objective question formats in use.

These factors resulted in the establishment of a closed-book written examination to accompany the open-reference examination already in place, oral questioning as part of the plant walkthrough examination and a revised grading criteria during the simulator examination. This modification of the testing metrodology was incorporated into revision 1 of the Peer Evaluator Standards. The phase IIi examinations were conducted from May 23 through October 10, 1991. The phase III period includes the retesting of personnel who failed the initial phase III examinations. A toial of 13 supervisors, 36 operators and seven Shift Technical Engineers participated in the phase III examination process. The examinations were jointly administered and independently evaluated by Peer Evaluators from SRS and a team of DOE Evaluators. The Westinghouse Peer Evaluators are certified supervisors or instructors at SRS who are trained in the peer evaluation examination process. The DOE Evaluators are Nuclear Regulatory Commission license examiners who are trained on $\mathrm{K}$ reactor systems and procedures. The examination program is modeled after the requalification examination program currently being conducted jointly by the NRC and licensed facilities at commercial nuclear power plants. This model is described in NUREG 1021, "OPERATOR LICENSING EXAMINER STANDARDS", Section ES-601. A detailed explanation of the development of the program and the training of the evaluators is provided in Appendix A. A detailed description of the examination administration is provided in Appendix $B$.

This report provides a description of the examination administration phase, the examination results, an analysis of the examination results (to iventify generic strengths and weaknesses), and general observations noted by the DOE examination team. 


\subsection{SUMMARY OF EXAMINATION RESULTS}

The Savannah River Restart Peer Evaluation examination consisted of three sections. An individual had to successfully pass all three sections of the examination to achieve an overall passing score. In the event that the individual failed to pass one section of the examination that person would be required to be remediated and retested in the failed section. In the event an individual failed two sections of the examination a WSRC review commititee, with DOE concurrence, determined whether that person would be requireo to retest on only the failed sections or on the entire examination. Each section of the examination tested different facets of the universe of knowledge and abilities that are necessary for safe and competent operation. Tha written section of the exam primarily tested mastery of knowledge. The in-plant section primarily tested the ability to perform safety-significant plant operations on an individual basis. The simulator section tested the individual's ability to function as part of a composite crew. Requirements for satisfactorily completing each section are described briefly in the following paragraphs.

\subsection{WRITTEN EXAMINATION}

The written examination used during phase I and II consisted of 40 open reference questions requiring a maximum of four hours to complete and was based on $750 \mathrm{~K} / \mathrm{As}$ identified as "restart K/As". During phase III, the examination scope was expanded to include all System and Emergency Plant Evolution (EPE) $K / A s$ in the SRS K/A catalog. As is practice in the NRC, examination development was based on $K / A$ s with an importance rating of 3.0 or greater (on a 0 to 5 scale) to emphasize the more significant areas. The examination was expanded to include 34 open reference questions and 66 knowledge based, closed reference questions and required a maximum of twelve hours to complete. An $80 \%$ minimum score was required to pass.

\subsection{JOB PERFORMANCE MEASURES}

Ten Job Performance Measures (JPMs) were administered to each individual. A JPM is a specific task or procedure that has been selected as important to the safety of the plant. The steps within the task that are important to the 
appropriate outcome of the task or directly impact plant safety are designated critical steps. During phase I and II the individual was required to satisfactorily perform a minimum of eight JPMs ( $80 \%)$. However, during phase III oral questions were asked following each JPM and the minimum passing score of $80 \%$ was determined by allotting $75 \%$ for JPM performance and $25 \%$ for oral question performance. Completion of the JPM section normally required from five to eight hours.

\subsection{SIMULATOR EXAMINATION}

The examination for each crew consisted of four to six individual simulator scenarios as determined by the number of operators in the crew being examined. Each simulator scenario required the crew to respond to a normal event (typically the recovery of an out of specification condition in the reactor flux distribution), an instrument and/or component failure, and a major plant transient such as a Loss of Coolant Accident or Loss of Off-site power.

Supervisors were required to participate in a minimum of two scenarios in the simulator, acting as both the Central Control Room Supervisor and as the Shift Manager. Operators were required to participate in a minimum of two scenarios, assigned to one of the three panel positions and taking "significant operator actions". Evaluations of both the crew as a whole and each individual were performed. The failure of a crew in the simulator section did not require that all the individual members of the crew correspondingly fail the simulator section of the exam, but rather the crew would be required to be remediated and retested via a crew simulator examination prior to restart.

During phase I and II, Individual Simulator Critical Tasks (ISCTs) and Crew Competencies were used to evaluate the individuals and the crew. Individuals failed the simulator section if they failed to perform an ISCT associated with their area of responsibility. ISCTs are considered to be so important to plant safety that the safe, competent operator must demonstrate absolute mastery (i.e., 100\% satisfactory performance of each task). Crews failed the simulator section if an ISCT was not performed correctly by an individual operator and other members of the crew were aware or should have 
been aware of the error and failed to properly mitigate the situation (normally by another operator performing the ISCT). Also, if the crew received a rating of " 1 " (on a 1 to 3 scale) in two areas of a competency, that competency was rated unsatisfactory. With an unsatisfactory rating in any one of six competencies, the crew failed. These competericies reflect the major knowledge and ability requirements for certified operators and STES during a dynamic simulator examination. Each cumpetency has been divided into several rating factors containing descriptive behavioral anchors for the evaluator to use for assessing performance.

During Phase III, Individual Competencies were used rather than Crew Competencies to allow a more in-depth evaluation of the individual. ISCTs and Individuai Competencies were used to evaluate the performance of the operators. Individuals failed the simulator portion of the examination if they failed to perform an ISCT associated with their area of responsibility or if a rating of less than 1.8 (out of a possible 3.0 ) was received in any one of the six competencies. Crews were evaluated using ISCTs as before.

\subsection{OVERALL RESULTS}

During the three phases of testing, a total of 73 individuals participated with the following certification background; 46 Central Control Room Operators (CCROs), 19 Central Control Room Supervisors (CCRSs), and 8 Shift Technical Engineers (STES). The overall results are as follows: of the 73 individuals who participated in one or more phases of the examinations, 47 individuals ( 28 CCROs, 12 CCRSs, and 7 STEs), comprising 5 crews, have successfully completed the phase III examination. of the 30 individuals who did not compiete the phase III examination, their disposition is as follows:

- 1 CCRO voluntarily withdrew during phase I,

- 4 CCROs and 3 CCRSs failed phases I \& II,

- 2 CCROs, 3 CCRSs and 1 STE passed phases I \& II, but were not presented for phase III testing,

- 3 CCRSs were presented for initial testing during phase II and were tested at the CCRO level. 2 individuals passed the examination, 1 failed. Subsequently, all individuals have been reassigned to positions outside of operations and were not presented for phase III testing,

- 3 CCROs and 1 CCRS voluntarily withdrew during phase III, and

- 5 CCROs failed to successfully complete phase III. 
OVERALL RESTART EXAM RESULTS BY PHASE

PHASE I

PHASE II

PHASE III

PASS FAIL TOTAL

PASS FAIL TOTAL

PASS FAIL TOTAL

\begin{tabular}{|c|c|c|c|c|c|c|c|c|c|}
\hline $\begin{array}{l}\text { OVERALL RESULTS } \\
\text { (Test Population) }\end{array}$ & $\begin{array}{r}58 \% \\
(28)\end{array}$ & $\begin{array}{l}42 \% \\
(20)\end{array}$ & $\begin{array}{l}100 \% \\
(48)\end{array}$ & $\begin{array}{l}76 \% \\
(22)\end{array}$ & $\begin{array}{l}24 \% \\
(7)\end{array}$ & $\begin{array}{l}100 \% \\
(29)\end{array}$ & $\begin{array}{l}73 \% \\
(36)\end{array}$ & $\begin{array}{l}27 \% \\
(13)\end{array}$ & $\begin{array}{l}100 \% \\
(49)\end{array}$ \\
\hline $\begin{array}{l}\text { WRITTEN EXAM } \\
\text { (Test Population) }\end{array}$ & $\begin{array}{l}77 \% \\
(37)\end{array}$ & $\begin{array}{l}23 \% \\
(11)\end{array}$ & $\begin{array}{l}100 \% \\
(48)\end{array}$ & $\begin{array}{l}50 \% \\
(5)\end{array}$ & $\begin{array}{l}50 \% \\
(5)\end{array}$ & $\begin{array}{l}100 \% \\
(10)\end{array}$ & $\begin{array}{l}85 \% \\
(40)\end{array}$ & $\begin{array}{l}15 \% \\
(7)\end{array}$ & $\begin{array}{l}100 \% \\
(47)\end{array}$ \\
\hline $\begin{array}{l}\text { IN-PLANT JPMS } \\
\text { (Test Population) }\end{array}$ & $\begin{array}{l}85 \% \\
(41)\end{array}$ & $\begin{array}{l}15 \% \\
(7)\end{array}$ & $\begin{array}{l}100 \% \\
(48)\end{array}$ & $\begin{array}{l}75 \% \\
(6)\end{array}$ & $\begin{array}{l}25 \% \\
(2)\end{array}$ & $\begin{array}{c}100 \% \\
(8)\end{array}$ & $\begin{array}{l}83 \% \\
(15)\end{array}$ & $\begin{array}{l}17 \% \\
(3)\end{array}$ & $\begin{array}{l}10 \\
(1\end{array}$ \\
\hline $\begin{array}{l}\text { SIMULATOR } \\
\text { INDIVIDUALS } \\
\text { (Test Populacion) }\end{array}$ & $\begin{array}{l}79 \% \\
(38)\end{array}$ & $\begin{array}{l}21 \% \\
(10)\end{array}$ & $\begin{array}{l}100 \% \\
(48)\end{array}$ & $\begin{array}{r}91 \% \\
(20)\end{array}$ & $\begin{array}{l}9 \% \\
(2)\end{array}$ & $\begin{array}{l}100 \% \\
(22)\end{array}$ & $\begin{array}{l}98 \% \\
(46)\end{array}$ & $\begin{array}{l}2 ; \% \\
(1)\end{array}$ & \\
\hline $\begin{array}{l}\text { CREWS } \\
\text { (Test Population) }\end{array}$ & $\begin{array}{l}60 \% \\
(3)\end{array}$ & $\begin{array}{l}40 \% \\
(2)\end{array}$ & $\begin{array}{r}100 \% \\
(5)\end{array}$ & $\begin{array}{l}67 \% \\
(2)\end{array}$ & $\begin{array}{l}33 \% \\
(1)\end{array}$ & $\begin{array}{c}100 \% \\
(3)\end{array}$ & NA & NA & \\
\hline
\end{tabular}

During phases I and II Shift Technical Engineers (STEs) were evaluated at the supervisor (CCRS) level. Because of demonstrated weaknesses in command and control and in analyzing overall plant status, due in part to a lack of operational experience, the role of the STE has been redefined. The decision was made not to "certify" the STEs. They remain on shift to advise the certified supervisor and contribute a strong fundamentals knowledge. Because of this, the evaluation of STEs during phase III was limited to their redefined roles. Observations of the STEs' crew interactions were made during the simulator exam and in most cases crew perf'irmance was enhanced. An expanded written examination was developed and administered to the STES by WSRC. The DOE Peer Evaluation team reviewed and approved the examination and documented the grading. Results of the STE evaluations are not included in phase III data.

A detailed breakdown of the examination results may be found in Table 2-1 for phases I and II and in Table 2-2 for phase III. A detailed analysis of the examination results is provided in Section 3 of this report. 
TABLE 2.1 Overal1 Phase I and II Examination Results Summary

EXAMINATION TYPE

WRITTEN-CCRO

WRITTEN-CCRS

WRITTEN-STE

WRITTEN-ALL

NOTE:

JPM-CCRO

JPM-CCRS

JPM-STE

JPM-ALL

NOTE:

SIMULATOR-CCRO

SIMULATOR-CCRS

SIMULATOR-STE

SIMULATOR-AIL

$23 / 27$

$15 / 15$

$6 / 6$

$44 / 48$

$24 / 27$

$12 / 15$

$6 / 6$

$42 / 48$

OR GREATER

$25 / 27$

$14 / 15$

$6 / 6$

$45 / 48$

NOTE: PASSING SCORE BY POSITION IS BASED ON ISCTS

SIMULATOR-CREW

$5 / 5$

NOTE: PASSING SCORE FOR CREW IS BASED ON ISCTS

$4 / 5 \quad 80 \%$

SIMULATOR-CREW

NOTE:

$85 \%$

$80 \%$

$100 \%$

$88 \%$

$85 \%$

$100 \%$

$100 \%$

$92 \%$

$94 \%$

$100 \%$

\%PASSED

AVERAGE SCORE

$85 \%$

$85 \%$

$89 \%$

$86 \%$

$87 \%$

$91 \%$

$87 \%$

$88 \%$

NA

NA

NA

NA

NA

NA 
TABLE 2.2 Overall Phase III Examination Results Summary

EXAMINATION TYPE

WRITTEN-CCRO

WRITTEN-CCRS

WRITTEN-ALL

NOTE: PASSING SCORE IS $80 \%$ OR GREATER

JPM-CCRO

JPM-CCRS

JPM-ALL

NOTE:

$28 / 34$

$12 / 13$

$36 / 47$

$12 / 15$

$3 / 3$

$15 / 18$
\#PASSED/\#TOOK EXAMS

SIMULATOR-CCRO

SIMULATOR-CCRS

SIMULATOR-ALL

NOTE: PASSING SCORE BY POSITION IS

$34 / 35$

$12 / 12$

$46 / 47$
\%PASSED

$82 \%$

$92 \%$

$77 \%$

$80 \%$

$100 \%$

$83 \%$

AVERAGE SCORE

$78.0 \% *$

$88.2 \%$

$79.6 \%$

$85.1 \%$

$89.6 \%$

$85.9 \%$

* Average :core for only "Certified" CCROs (excluding failures) was $83.5 \%$. 


\subsection{ANALYSIS OF EXAMINATION RESULTS}

rollowing the examination period, a data base was established to provide in-depth analysis of the examination results for all seventy-three individuals. This section provides the findings generated during the analysis of examination results.

\subsection{WRITTEN EXAMINATION}

All of the written examination questinns that were asked on the examinations were reviewed and analyzed. The following categories were tabulated to support the analysis: (1) total number of individuals who answered the question, (2) total number of correct responses, (3) total number of incorrect responses, and (4) percentage of individuals who correctly answered the question. The written examinations administered during phase III of the operator assessment program were fundamentaliy different from those administered during phases I and II. The overall scope of the written examination changed, as well as the format used. The differences in examination composition prevents a useful raw score trend analysis between different phases of the examination. The phase III examinations, similar to an NRC initial examination, were more comprehensive, thorough, and discriminatory than the examinations administered during phases I or II.

Four (4) CCRO written examinations were given during phase III testing. WSRC evaluated the results of individuals who failed one or more sections of the examination and determined their remediation schedule on an individual basis. Individuals were then presented for reexamination at varying times during subsequent exams. All individuals were remediated for minimum of 30 days prior to retesting.

- Exam 1 was administered to seventeen candidates for an initial attempt.

- Exam 2 was administered to eleven candidates, eight for an initial attempt and three who had failed the previous exam.

- Exam 3 was administered to fourteen candidates, nine for an initial attempt and five who had failed one of the previous exams.

- Exam 4 was administered to ten candidates. Eight had failed one of the previous exams and two who had failed twice before. 
Two (2) CCRS written examinations were given during phase III testing.

- Exam 1 was adminisicered to four candidates for an initial attempt.

- Exam 2 was administered to ten candidates, nine for an initial attempt and one who had failed the previous exam.

PHASE III WRITTEN EXAMINATION RESULTS SUMMARY

\begin{tabular}{|c|c|c|c|c|c|}
\hline EXAMINATION & \#PASSED/\#TOOK EXAM & \%PASSED & CLSD SCORE & OPEN SCORE & AVERAGE \\
\hline $\begin{array}{lll}\text { EXAM } & 1 & \text { CCRO } \\
\text { EXAM } & 2 & \text { CCRO } \\
\text { EXAM } & 3 & \text { CCRO } \\
\text { EXAM } & 4 & \text { CCRO }\end{array}$ & $\begin{array}{l}8 / 17 \\
9 / 11 \\
5 / 14 \\
6 / 10\end{array}$ & $\begin{array}{l}47 \% \\
82 \% \\
36 \% \\
60 \%\end{array}$ & $\begin{array}{l}76.3 \% \\
85.2 \% \\
77.4 \% \\
79.2 \%\end{array}$ & $\begin{array}{l}75.0 \% \\
79.4 \% \\
72.8 \% \\
77.2 \%\end{array}$ & $\begin{array}{l}75.9 \% \\
83.2 \% \\
76.0 \% \\
78.6 \%\end{array}$ \\
\hline $\begin{array}{lll}\text { EXAM } & 1 & \text { CCRS } \\
\text { EXAM } & 2 & \text { CCRS }\end{array}$ & $\begin{array}{c}2 / 4 \\
10 / 10\end{array}$ & $\begin{array}{r}50 \% \\
100 \%\end{array}$ & $\begin{array}{l}81.4 \% \\
92.5 \%\end{array}$ & $\begin{array}{l}83.6 \% \\
89.2 \%\end{array}$ & $\begin{array}{l}82.1 \% \\
91.4 \%\end{array}$ \\
\hline
\end{tabular}

NOTE: PASSING SCORE IS $80 \%$ OR GREATER

It is significant to note that, in five of the six examinations, average scores were slightly higher in the closed reference section than in the open reference section, indicating that both formats were successful in identifying poor performance.

A total of twelve written examinations were developed during phase III, two CCRS and four CCRO tests each consisting of an open reference exam and a closed reference exam. All twelve of the written examinations administered during phase III were reviewed and analyzed both individually and collectively. No specific areas of weakness were conclusively identified by analysis of knowledge headers ( $K 1$ through $K 6$ ), ability headers ( $A 1$ through A4), and generic knowledge/abilities either within or across examinations.

A further analysis was conducted on the examination results that included groupings by Plant Systems, Emergency Plant Evolutions (EPEs), and Plant Wide Generics using as a basis operators only, supervisors only, and both groups combined. Al1 examinations, including previous failures, were incorporated in the analysis to identify training program trends. Table 3.1 , generic weaknesses, provides a list of those systems and evolutions that are one standard deviation below the average score. The table also indicates which operator category had difficultly with the identified system or evolution. 
Table 3.2, generic strengths, provides similar data for those systems or evolutions that are one standard deviation above the average score.

An analysis performed on phase I and II examinations indicated less than satisfactory knowledge in the following Plant Systems and Emergency Plant Evolutions:

- Emergency Electrical Power System,

- Cooling Water Gamma Monitoring System,

- Disassembly Basin and Disassembly Basin Cooling and Filtration System,

- High Off-Site Release Rate,

- Control Room Abandonment,

- Partial or Complete Loss of AC Power, and

- Inadvertent Reactivity Addition.

Four of the seven areas of weakness during phase I and II were in Emergency Plant Evolutions. It was also noted that a general area of weakness identified within Plant Systems and Emergency Plant Evolutions was the ability to accurately use Technical Specifications. Using phase III (Tables 3.1 and 3.2) data, five of the seven weaknesses identified in earlier phases had been remediated and two of those five had become generic strengths for supervisors. The areas of Emergency Electrical Power and Inadvertent Reactivity Addition remained overall weaknesses throughout the testing. Phase III results a? so identified the area of Building Radiation Monitors as an overall weakness.

The written examination appeared to be the most discriminatory evaluation tool to identify the unsatisfactory operator at Savannah River. Because of this, analysis can be flawed by the inclusion of data from tests given prior to successful remediation and from individuals who did not complete the program. The analysis most effected is for the CCRO, where 24 of 52 written examinations were failed. For example, while the average score on the CCRO written is $78.0 \%$, the average score for the "certified" CCROs is $83.3 \%$. Table 3.3 includes only the 28 written examinations passed by certified CCROs to identify strengths and weaknesses for those individuals, as opposed to the training program analysis done above. Because the standard deviation for this database is $15.8 \%$, strengths and weaknesses are based on an arbitrary $+-10 \%$ deviation from the CCRO average score of $83.3 \%$ in an attempt to better utilize the data. Three systems were not categorized due to insufficient test data. 
System and Emergency Plant Evolution titles are listed for reference in Appendix B, Tab 7.

\subsection{JOB PERFORMANCE MEASURES}

During the performance of the examination, a total of 80 unique Job Performance Measures (JPMS) were administered. A JPM comprises a safety significant task that is evaluated by observing operator performance either in the simulator or in the plant. Tasks normally assigned to CCROs were also tested on the CCRS and STE level, since these positions could be expected to supervise the performance of these tasks. CCROs were not required to perform tasks normally assigned to the CCRS or STE positions.

Job Performance Measures (JPMs) were administered to eighteen individuals (15 CCRO, 3 CCRS) during phase III. Candidates who participated in phase I and II were not retested on in -plant JPMs because JPM examination scope had not changed. Only one of the fifty JPMs used during phase III was newly developed and the addition of two oral, closed reference questions was the only change in JPM exam format.

\section{PHASE III JPM EXAMINATION RESULTS SUMMARY}

\section{POSITION \#PASSED/\#TOOK EXAM JPM SCORE QUESTION SCORE AVERAGE SCORE}

$\begin{array}{lcccc}\text { CCRS } & 3 / 3 & 90.0 \% & 88.3 \% & 89.6 \% \\ \text { CCRO } & 12 / 15 & 90.0 \% & 71.8 \% & 85.4 \%\end{array}$

The table above shows how the addition of oral questions reduced overall JPM scores. Two of the three CCRO candidates who failed in-plant JPMs performed eight of ten JPMs satisfactorily. Their failure resulted from incorrectly answering a number of the newly added oral questions. In al1, ten of the 15 CCROs examined answered less than $80 \%$ of the oral questions correctly. Because of this generic weakness, an analysis of phase III results was performed to reevaluate the decision not to retest individuals who completed JPMs during phase I and II. The anaiysis confirmed that the expanded written examination used during phase III adequately screened the areas of weakness identified by JPM oral questions. The following forms the bases for this judgment: 
- All three CCRO candidates who failed the JPM portion of phase III also failed the expanded written examination.

- Eight of the ten CCRO candidates who scored less than $80 \%$ on JPM questions also failed the expanded written examination.

Five JPMS ( $10 \%$ of the JPMs administered) were performed at less than an eighty percent success rate during phase III. The 1 ist of these JPMs is provided in Table 3.4. Table 3.5 lists JPMs which had oral questions answered at less than an $80 \%$ success rate. Results from phase I and II indicated that the CCRS/STEs failed a disproportionate number of JPMs. General areas of weakness for the supervisory positions had been the bypassing of safety circuits and Technical Specification interpretation. A generic area of weakness across all certified positions had been the ability to perform tasks requiring calculations. Phase III results, Tah? es 3.4 and 3.5 , document overall satisfactory performance by supervisors in all but one JPM, administrative requirements of Shift Turnover. Operators again demonstrated a weakness in tasks requiring calculations. In addition, it is significant to note that the area of Emergency Electrical Power was identified as a weakness in both the JPM and the written examination analysis.

\subsection{SIMULATOR EXAMINATION}

Individual Simulator Critical Tasks (ISCTs) were used to evaluate each individual during all phases of testing. Competencies were used to evaluate crews during phase I and II and to evaluate individuals during phase III. Comparisons can be made, however, and reveal recurring weaknesses throughout the simulator examination process.

Following phase I and II an analysis was performed on crew competencies compiled from the simulator examination. Each crew competency has three or four major rating factors. Each rating factor has a one-to-three grading scale (three being the high score). The full report on crew competencies is provided in Table 3.6 .

During phase III simulator examinations, one individual failed Jue to overall competencies. Several others, however, demonstrated weaknesses in one or more of the rating factors associated with a competency. The most significant generic weakness roted was in USE OF PROCEDURES, an area also 
identified during earlier phases. The following areas had five or more individuals who received a rating of 1.0 on a competency rating factor:

- COMPLIANCE/USE OF PROCEDURES AND TECHNICAL SPECIFICATIONS,

- UNDERSTANDING/INTERPRETATION OF ANNUNCIATORS/ALARM SIGNALS,

- UNDERSTANDING PLANT RESPONSE.

Table 3.7 reports the number of individuals who demonstrated unsatisfactory performance in each of the competency areas identified.

An analysis of Individual Simulator Critical Tasks (ISCTs) during phase III revealed no general areas of weakness. The only ISCT failed during phase III was the following:

- Data Operators' ability to correct Radial Flux (flux Tilt) problems.

Several areas of weakness which had been identified during phase I and II were observed and successful remediation was confirmed. These areas are listed below to depict major areas of improvement.

- Nuclear Console Operators' ability to maintain control of reactor power level and flux distribution while correcting Roof Top Ratio (flux Tilt) problems,

- Operators'/crews' ability to operate the Electrical Distribution Control Panel correctly and in a timely manner,

- Supervisors' ability to maintain overall control of crew response during events and to provide proper oversight of off-site communications (EAL declarations), and

- Supervisors' ability to properly transition to higher priority ACCs (Abnormal Condition Control Procedures) during an event. 
TABLE 3.1 Phase III Written Examination Summary of Generic Weaknesses SYS\# CATEGORY

POSITION

101

105

106

119

122

132

202

208

Reactor Scram System

CCRS

Emergency Electrical Power

Compressed Air

COMBINED

Building Radiation Monitors

B? anket Gas

CCRO

COMBINED

Domestic and Fire Protection

CCRO

Water

CCRO

Inadvertent Reactivity Addition

CCRS

Charge Discharge Operations

CCRS

TABLE 3.2 Phase III Written Examination Summary of Generic Strengths SYS\#

CATEGORY

POSITION

102

111

113

116

126

127

128

129

203

207

Supplementary Safety System

COMBINED

Control and Safety Rod System

CCRS

Contaminated Water Removal and

Disposal System

CCRS/CCRO

Process Water Pump and Motor

Lubrication Oil System

CCRS

Reactor Effluent Water

Monitoring System

Reactor Tank Pressure Relief

CCRS

System

River Water and PAR Pond Pumps

and Valves

Disassembly Basin and

CCRS/CCRO

Disassembly Basin Cooling/

Filtration System

CCRS

Fuel Failure

CCRS

High Offsite Release Rate

CCRS

CCRS 
IABLE 3.3 System Analysis for Certified CCROs

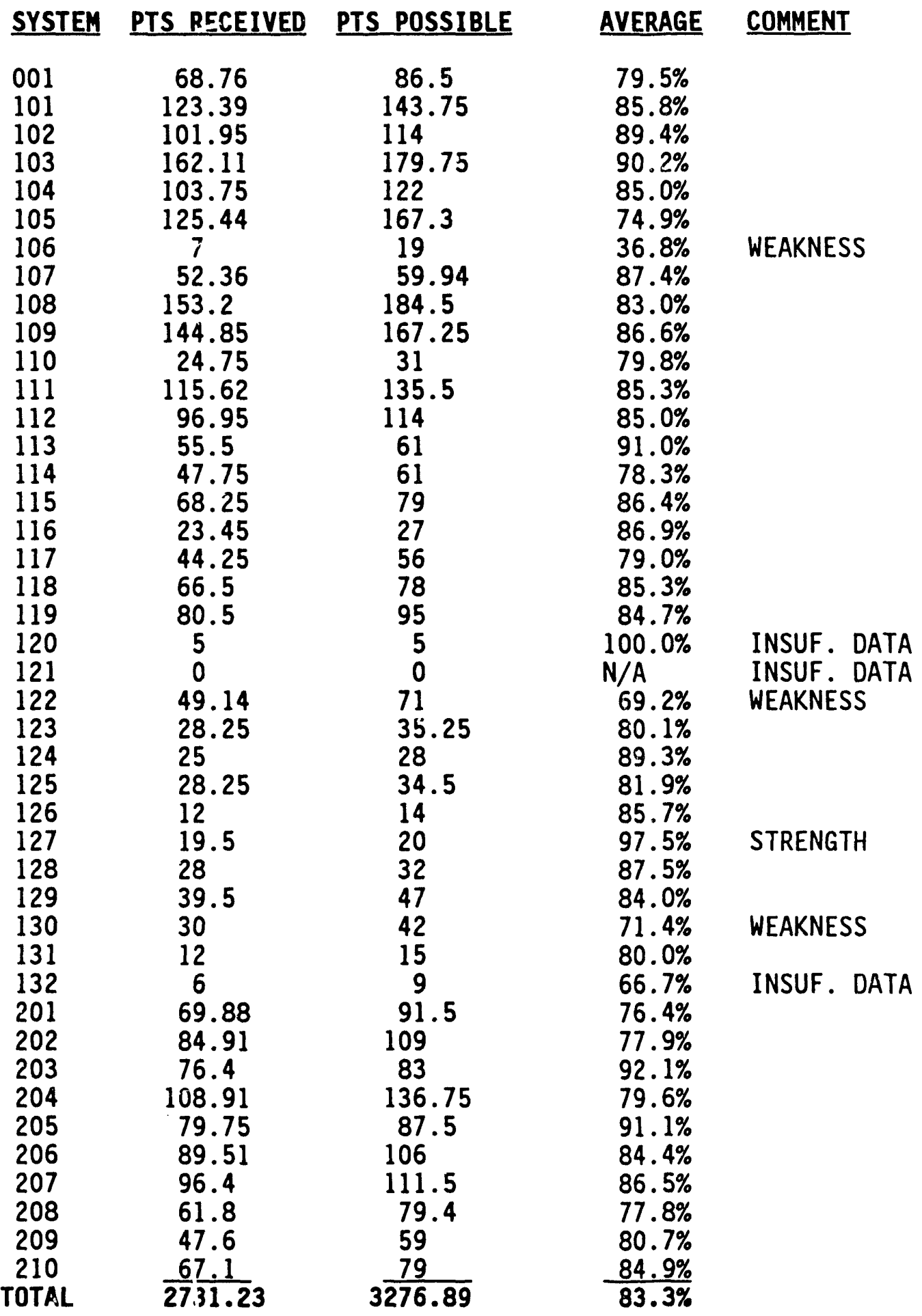

System and Emergency Plant Evolution titles 1isted in Appendix B, Tab 7. 
TABLE 3.4 Phase III JPMs with Average Success Rate of $<80 \%$

$\underline{\text { JPM\# }}$ JPM TITLE

POSITION

$001 A 103.10$

103G13.1A

$111 \mathrm{Al} .02 .3 \mathrm{~B}$

$111 \mathrm{G} .11 .1 \mathrm{~A}$

$115 \mathrm{Al} .01 .1 \mathrm{~B}$

Shift Turnover

Start Booster Pump

CCRS

Tilt-Dynamic

Al1

Technical limit- AAVG

CCRO

MRS operation $(M i-20)$

CCRO

CCRO

TABLE 3.5 Phase III JPMs with Oral Question Average Success Rate of $<80 \%$

JPM\#

$101 \mathrm{~A} 214.1 \mathrm{~A}$

$102 \mathrm{~A} 4.01 .1 \mathrm{~B}$

$103 \mathrm{G} 13.1 \mathrm{~A}$

$10769.1 .1 \mathrm{~A}$

$109 \mathrm{Al} .04 .1 \mathrm{~A}$

$111 \mathrm{Al} .02 .3 \mathrm{~B}$

$111 G .11 .1 \mathrm{~A}$

$112 G .13 .1 \mathrm{~A}$

$112 G .13 .2 \mathrm{~A}$

$115 \mathrm{~A} 1.01 .1 \mathrm{~B}$

$118 \mathrm{A2} .02 .3 \mathrm{~A}$

201A1.03.1B

201Al.11.1A

$210 \mathrm{Al} .02 .1 \mathrm{~B}$

210A1.02.2B
JPM TITLE

Septifoil Scram

Failure of the Safety Rods to Scram

Start Booster Pump

Spray Pump Operation

Abnormal Reactor Overflow Supply

Correcting Radial Tilt

Technical limit - AAVG

CW Recirculating Pump start

CW Recirculating Pump shutdown

MRS operation (MC-20)

Instantaneous D20

Console - trip SSS, drive rods

Respond to Heat Exchanger Flow Down 10\%

Manually start GM \#1 (MC-8)

Loss of Transformer Room (EE-425)
POSITION

A11

CCRO

Al1

A11

CCRO

CCRO

CCRO

All

Al1

CCRO

Al1

CCRO

ALL

CCRO

CCRO 
TABLE 3.6 Crew Competency Analys is by Phase

Competency Areas

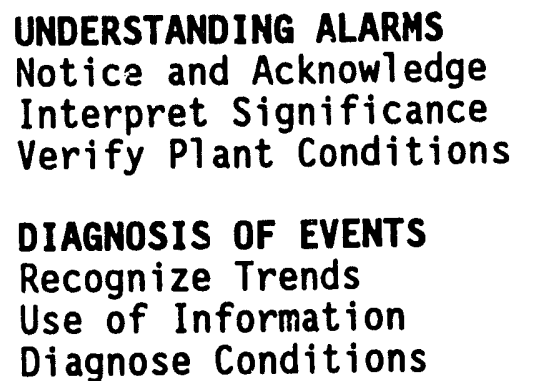

PROCEDURES \& TECH SPECS

Refer to Procedures

Implement Procedures

Recognize Entry MC-2/MC-3

Tech Spec Compliance

CONTROL BOARD OPERATIONS

Locate Controls

Manipulate Controls

Take Manual Control

COMMUNICATIONS

Exchange Information

Interact with others

Team Decision Making

UNDERSTANDING PLANT RESPONSE

Interpret Indications

Understanding Operations

Effect of Actions on Plant
PHASE

Average Score

I

II

2.6

3.0

2.8

2.8

3.0

2.3

2.9

2.6

2.45

1.8

2.6

2.0

3.0

2.0

1.9

2.8

1.7

2.4

2.3

2.35

1.3

2.7

1.7

1.25

2.75

2.2

2.8
2.7

3.0

2.6

2.6

2.7

1.7

2.85

2.15

2.8

2.0

2.6

2.0

1.3

2.7

1.65

2.0

2.65

2.0

2.3

2.25

2.0

1.9

2.7

2.35 
TABLE 3.7 Individual Competency Analysis for Phase III

Competency Rating Factor

Average Score

CCRS

2.82

UNDERSTANDING ALARMS

Notice and Acknowledge

Interpret Significance

Verify Plant Conditions

DIAGNOSIS OF EVENTS

Recognize Trends

Use of Information

Diagnose Conditions

PROCEDURES \& TECH SPECS

Refer to Procedures

Implement Procedures

Recognize Entry MC-2/MC-3

Tech Spec Compliance

CONTROL BOARD OPERATIONS

Locate Controls

Manipulate Controls

Respond to Instruments

Take Manual Control

COMMUNICATIONS

Exchange Information

Interact with Others

Team Decision Making

UNDERSTANDING PLANT RESPONSE

Interpret Indications

Understanding Operations

Effect of Actions to Plant

DIRECTING OPERATIONS

Timely Actions

Safe Directions

Oversight

Crew Feedback

* CCRS population $=12$

CCRO population $=34$
$2.50 \quad 2.60$

$3.00 \quad 2.94$

$2.92 \quad 2.83$

$2.83 \quad 2.76$

$2.83 \quad 2.54$

$2.75 \quad 2.94$

$2.83 \quad 2.91$

$2.82 \quad 2.82$

$2.75 \quad 2.89$

$2.58 \quad 2.89$

$3.00 \quad 2.57$

2.83

2.94

NA $\quad 2.92$

NA $\quad 2.97$

NA $\quad 2.83$

NA $\quad 2.94$

NA $\quad 2.97$

$2.70 \quad 2.72$

$2.83 \quad 2.60$

2.58

2.75

2.77

2.80

2.95

3.00

2.92

2.92

2.68

2.71

2.51

2.80

2.70

2.67

2.58

2.75

2.92

NA

NA

NA

NA

NA

Number of individuals rated $1.0^{*}$

CCRS CCRO TOTAL

$\begin{array}{lll}2 & 2 & 4 \\ 0 & 0 & 0 \\ 0 & 1 & 1\end{array}$

$\begin{array}{lll}0 & 0 & 0 \\ 1 & 0 & 1 \\ 0 & 0 & 0\end{array}$

$\begin{array}{lll}1 & 1 & 2 \\ 1 & 2 & 3 \\ 0 & 2 & 2 \\ 0 & 1 & 1\end{array}$

$\begin{array}{lll}\text { NA } & 0 & 0 \\ \text { NA } & 2 & 2 \\ \text { NA } & 0 & 0 \\ \text { NA } & 0 & 0\end{array}$

$\begin{array}{lll}0 & 0 & 0 \\ 1 & 1 & 2 \\ 0 & 0 & 0\end{array}$

$\begin{array}{lll}0 & 3 & 3 \\ 0 & 2 & 2 \\ 0 & 1 & 1\end{array}$




\subsection{GENERAL OBSERVATIONS}

During each week of the assessment, the DOE Evaluators prepared a summary of general observations which address both the strengths and weaknesses that were observed during the week. This section provides a synopsis of those observations. Although a number of operator weaknesses have been noted, none of the weaknesses, whether considered individually or in aggreoate, would adversely impact the ability of the operators to safely operate the reactor. Many of the comments are included as the result of a commitment to continue improvement of operator performance beyorid the presently achieved safe standard. The comments are included to assist WSRC address areas where operator performance can be improved.

\subsection{STRENGTHS}

The following strengths were observed during the examinations:

- The general level of training, confidence, and teamwork demonstrated by the individual crews was significantly improved from the examinations administered during the summer and fall of 1990. The crews responded to the plant transients presented them in a methodical, we 11 coordinated manner. The execution of procedures was noticeably more crisp, exact, and deliberate than observed on previous examinations.

- Apart from the initial crew tested, the awareness and acknowledgment of alarms improved greatly as the simulator testing phase was conducted among the other crews.

- In general, the operating crews accepted their redefined responsibilities in a professional manner and seemed genuinely receptive to the new concept of operation requirements that is being implemented at Savannah River.

- The professional demeanor of the crews throughout the examinations was commendable. The operators were under a significant amount of stress, yet they maintained their composure and perspective, and approached each problem presented them in a deliberate and methodical manner.

\subsection{WEAKNESSES}

The following weaknesses were observed:

- Although communications between crew members improved significantly from the testing conducted in the summer and fall of 1990, communications continues to be a weakness which requires attention and training. Specifically, there were several instances when operatuors did not relay important information to other crew members or when operators used 
imprecise words and phases which did not accurately convey the conditions of the plant. Continued areas of weakness are as follows.

- Directed messages are not consistently acknowledged to ensure that they aro received.

- Precision of communications tends to degrade during high stress situations. This adds an additional element of confusion.

- Operators are not cognizant of the overall importance of their reports so that high priority messages are being delayed by low priority (informational) messages.

- Understanding of electrical systems and theory also improved, however they are still observed as weaknesses.

- Some operators were unfamiliar with ine general plant layout and the location of various plant systems and equipment. As a general rule, these were people who had until recently been working exclusively at $P$ or $L$ reactor.

- Operutors demonstrated a general inability to perform routine control room calculations. The difficulties were due to math errors and an inability to determine the correct flow zone required by the calculation.

- Several observations were made concerning procedures and procedural compliance.

- Control Room procedures should be reviewed to improve their clarity and ease of use. On the last written examination, the operators were asked to determine the minimum ECS flow requirements using the table in Appendix 12 of MC- 6 . Half of the individuals that passed the exam could not correctly use the table. This table exemplifies how the layout of information and terminology can add to the complexity of task performance.

- $\quad$ SRS administrative procedures which ensure revisions to procedures are properly reviewed by the operators prior to assuming their shift have not been completely implemented by WSRC. There were occasions when revised procedures were placed in the simulator before the operators had the benefit of reviewing or training on the new material.

- Supervisors would not always refer to the correct procedure or the proper reference material to effectively diagnose or mitigate the plant transient.

- The absence of symptom based Emergency Operating Procedures detracted from the general command and control skills observed of the supervisors. 
- On several occasions supervisors tended to overclassify Emergency Action Levels (EAL's) under the erroneous assumptions that it is always better to declare a higher EAL. Supervisors often did not understand the implications of their actions.

- One section of supervisors allowed alarms to continue to ring without acknowledging or silencing the alarm. This became very distracting to the watch station and prevented focusing on plant conditions.

- The intensity of control room alarms detracted from the crew's ability to function effectively. Supervisors permitted operators to muffle audible alarms with their hands in an attempt to reduce noise levels.

- Operators were weak in their understanding of neutron flux monitoring equipment. Some operators were unable to properly read flux monitoring equipment and others were unable to predict the response of the equipment to expected changes in core reactivity levels.

- WSRC management is not screening unqualified operators from the examination process. 


\subsection{ONGOING SUPPORT ACTIVITIES}

Preceding and subsequent to $K$ reactor restart, the DOE evaluation team will work with WSRC to ensure continued operator safety. Activities presently scheduled to support this objective include:

- Retesting of operators/crews on an annual basis,

- Development of a Peer Evaluation Standard for initial certification and testing of operators who are presented for initial certification,

- Evaluation of symptom based Emergency Operating Procedure implementation,

- Evaluation of WSRC responses to this report and other activities that impact operator performance as appropriate. Activities to support this objective could entail additional operator testing, evaluation of classroom/simulator training, and/or evaluation of in-plant crew performance prior to or during startup.

Scheduling activities for these projects has not been finalized. 
॥

II

II

II

"

II

APPENDIX A

PROGRAM DEVELOPMENT PHASE 
APPENDIX A

PROGRAM DEVELOPMENT PHASE

This appendix provides a detailed discussion of the overall program development process. The purpose of the discussion is to provide the background information that is required to understand the development of content-valid examinations, the basis for the program standards, and the development of Peer Evaluation qualification standards. Specific areas addressed in the appendix include:

- Program Standards Development

- Content-Valid Examination Development Process

- Peer Evaluator Training

- DOE Evaluator Training

\section{A.1 PROGRAM STANDARDS DEVELOPMENT}

The overall goals of the development process were to develop an examination process that was: (1) valid in content, (2) relevant to the safety significant knowledge and abilities of the certified operators, and (3) capable of providing credibility because of similarities in the process used at SRS and the commercial nuclear industry.

The basic model selected for program development was the requalification program that is used by the NRC for licensed operators at commercial nuclear facilities, as defined in NUREG 1021, OPERATOR LICENSING EXAMINER STANDARDS, Revision 5. This model was selected because the requalification section of NUREG 1021 (ES-601) was deemed to be the most appropriate model for evaluating operator knowledge and abilities prior to restart. It emphasizes performancebased evaluations utilizing objective performance measures in lieu of the traditional oral questioning method. The validity of the examination material is tied directly to an analysis of the job requirements. Finally, the objectivity of the format lends itself to paraliel evaluations. 
A draft of the Peer Evaluator Standard was developed by DOE evaluators. The draft was reviewed by both DOE and Westinghouse management and revised based on their comments. Subsequently, the Peer Evaluator Standard was jointly approved by DOE and WSRC management.

The examination process administered during Phases I and II at SRS was consistent with the process used at commercial nuclear utilities to requalify nuclear power plant operators. In particular, areas in which there are no significant differences between NUREG 1021 and the Peer Evaluator Standard include:

- The passing criteria for all examination aspects (written, JPM, and Simulator examinations) are the same.

- Simulator and JPM examination formats, complexity, and number of examinations required are similar.

- Examination forms used at SRS meet commercial nuclear utility standards for format and required elements.

- The evaluation teams (DOE and Peer) meet the knowledge, experience, and training requirements specified in NUREG 1021.

- The examination structure, sequencing, and administration requirements are as specified in NUREG 1021.

- Similar to NRC written examinations, the Peer Evaluator Standard required that a sample plan be prepared for each written examination.

A summary of significant differences between NUREG 1021 and the Peer Evaluator Standard includes:

- NUREG 1021 utilizes an open reference examination ( 2 hours) and a static simulator written examination ( -2 hours). The static written examination was not included in the Peer Evaluator Standard. This type of examination requires extensive training of the operators on examination format. It was decided training time could be better utilized on technical content. In lieu of a static simulator written examination, a 4 hour open reference examination was administered during Phases I and II and was expanded to include a closed reference section during Phase III. The examinations used preestablished criteria for the percentages of questions requiring answers from memory, questions requiring reference material, and questions requiring the operator to synthesize multiple elements to obtain the correct answer.

- NUREG 1021 requires that at the completion of each Job Performance Measure (JPM) the operator must answer two oral, open reference questions. The open reference question portion of the examination was 
not included within the Peer Evaluator Standard. The bases for making this exclusion were:

- the written examination standard for SRS significantly exceeds the requirements of NUREG 1021 ,

- inclusion of questions would significantly lengthen the examination time,

- inclusion of questions would increase operator stress due to scheduling difficulties, and

- oral questioning does not support a performance-based testing methodology.

- NUREG 1021 was designed not only to relicense operating personnel at commercial nuclear utilities, but also to certify the facility as being capable of maintaining adequate standards of performance during internal evaluations. This "Programmatic" evaluation of the facility is an integral part of the NRC regulatory process. The process for programmatic evaluation of the operator training program was not included in the Peer Evaluator Standards since there is no regulatory basis for determining program acceptability.

Phase I and II examination results demonstrated that more discriminatory evaluation tools were needed to adequately screen unsatisfactory individuals. The scope of an NRC requalification examination is partially based on the assumption that each individual has previously passed an NRC initial examination and a satisfactory minimum level of knowledge has previously been assured. Results from Phases I and II indicated that assumptions concerning the pre-existence of a satisfactory minimum level of knowledge could not be made at the Savannah River Site. This mandated that further testing be patterned more toward an initial NRC license examination.

The NRC Requalification Examination differs from an initial license exam in three basic ways.

- A 40 question open reference written exam is used instead of a 100 question closed book exam. This is based on the fact that prior screening has been done and a certain minimum level of knowledge is known to already exist. The operator has already demonstrated a knowledge of reactor fundamentals, system design, interlocks and system interrelationships during his/her initial exam. The open book exam better examines the operator's ability to USE this knowledge.

- Crew competencies are evaluated instead of individual competencies. The operator, again, has previously been evaluated during his/her initial 
examination and has demonstrated the ability to communicate, operate controls, etc.

- Job Performance Measures (JPMs) with related questions are used instead of a comprehensive plant walkthrough oral exam. During his/her initial exam the operator demonstrated satisfactory system knowledge. The JPM evaluates the operator's ability to perform a specific task and implement facility procedures. The follow-up questions assure an understanding of the task performed.

Phase III examination criteria was again based on an NRC requalification style evaluation but incorporated several aspects of an initial NRC examination, as well. Program changes are summarized below.

- Phase I and II examinations were limited in scope to knowledges and abilities which were considered to be "very important for restart" and identified in the SRS K/A catalogue with a "*". After completion of those exams, $K$ Reactor restart was delayed and it was determined that sufficient training time existed to allow expansion of the testing boundaries. The K/A catalogue was revised by eliminating the " $\star$ " and instituting an importance rating scale that is based on the NRC K/A catalogue. Having made this change, the basis for the exam sampling plan became the entire $K / A$ catalogue. As is practice in the NRC, examinations were then developed using K/As with an importance rating greater than 3.0 to ensure the more significant knowledges and abilities were tested.

- The written examination was expanded to 100 questions of which approximately one third was open reference and the remaining two-thirds knowledge based, closed reference questions. Question format was also expanded to include essay, short answer, matching, and draw and label style questions.

- The simulator examination was expanded to require more instrument and component failures during each scenario, ensuring a more discriminatory examination of each individual operator. Operators were again evaluated on competencies, but on an individual basis instead of as a crew.

- Job Performance Measures (JPMs) were unchanged, but two knowledge based, closed reference questions were asked after each JPM and incorporated into the JPM grading criteria. Closed reference, vice open reference, questions provided evaluators with a greater assurance of task understanding without significantly lengthening the examination. Open reference questions have traditionally resulted in increased examination time and stress levels.

\section{A.2 CONTENT-VALID EXAMINATION DEVELOPMENT PROCESS}

Establishing a performance-based examination process presented a significant departure from established training and evaluation methods at SRS. The significance of this task should not be underestimated. Many obstacles 
had to be overcome in order to develop the program. The establishment of a performance-based evaluation methodology took approximately five years in the commercial nuclear utility industry, while at SRS this task had to be completed in less than five months. The training department and operating staff had to quickly adjust to a new format of testing and evaluation. No Job and Task Analysis from which to identify the required skills and knowledge base for certified operators existed. Resources to develop examination material were limited by the quantity and quality of the material and manpower availability.

The initial major step in developing the examination model was to establish the knowledge and skill requirements for the certified operators. Traditionally in commercial nuclear power plants, this step is performed by conducting a Job and Task Analysis (JTA) and using the JTA to establish the critical knowledge and skill requirements for the operating positions. With no JTA available, the approach taken at SRS utilized the "Knowledge and Abilities Catalog for Nuclear Power Plant Operators for Boiling Water Reactors", NUREG-1123, as the reference for developing an SRS specific knowledge/abilities (K/A) catalog.

The NRC K/A catalog is the document used by NRC examiners to establish safety significant knowledge and abilities. The major point of deviation between a JTA and a K/A catalog is that the JTA determines the full scope of knowledge and abilities necessary to perform a job (taking into account frequency, difficulty, and safety importance), while a K/A catalog takes into account only knowledge and abilities that are safety-related. Given that the objective of the task is to determine the readiness of the operators to "safely" operate the reactor systems, it was determined that the K/A catalog provided a high degree of validity in meeting the task objective.

Utilizing SRS training material and input from subject matter experts, the DOE Evaluators developed the draft K/A catalog. Following initial development of the K/A catalog by the DOE Evaluators, the catalog was validated by a task force of Westinghouse subject matter experts from Operations and Training.

\section{A. 5}


Thirty-two reactor plant systems and ten Emergency Plant Evolutions having safety significance were identified. Additionally, 28 knowledge and abilities were identified as generic to all SRS production reactors and were grouped under the heading of "Plant-Wide Generics". The validated catalog became the basis for the development of all examination material.

Each reactor plant system lists all required safety significant knowledge grouped under one of six headings:

K1 Knowledge of the physical connections and/or cause-effect relationships between the system and the following:

K2 Knowledge of electrical power supplies to the following:

K3 Knowledge of the effect that a loss or malfunction of the system will have on the following:

K4 Knowledge of system design feature(s) and/or interlocks which provide for the following:

K5 Knowledge of the operational applications of the following concepts as they apply to the system:

K6 Knowledge of the applicable performance, design attributes and the effects of malfunctions of the following system components:

Similarly, each reactor plant system lists all required safety significant abilities grouped under one of four headings.

A1 Ability to predict and/or monitor changes in parameters associated with operating the system controls including:

A2 Ability to (a) predict the impacts of the following malfunctions or operations on the system; and (b) based on those predictions, use procedures to correct, control, or mitigate the consequences of those abnormal conditions or operations:

A3 Ability to monitor automatic operations of the system including:

A4 Ability to manually operate and/or monitor in the control room: Additionally, each reactor plant system has identified 15 system generic K/As.

Each Emergency Plant Evolution identifies all required knowledge under one of three categories:

EKl Knowledge of the operational implications of the following concepts as they apply to the event: 
EK2 Knowledge of the interrelations between the event and the following:

EK3 Knowledge of the reasons for the following responses as they apply to the event.

Each Emergency Plant Evolution identifies all required abilities under one of two categories:

EAl Ability to operate and/or monitor the following as they apply to the event:

EA2 Ability to determine and/or interpret the following as they apply to the event.

Each Emergency Plant Evolution identifies 12 generic K/As.

Once the K/A catalog was developed, sample plans were prepared for the written, JPM, and simulator examinations. A sample plan is an outline/blueprint to ensure that the examination is a content valid test. The sample plan ensures a consistent balance of questions between the major $K / A$ categories (i.e., reactor plant systems, emergency plant evolutions, and plant wide generics) and $K / A$ headers (e.g., $K 1$ through $K 6$ ) to document the content validity of the examination. Each category within the sample plan had mandated percentage requirements based upon the category's overall importance to plant safety. The sample plans also ensured consistency between each examination and that an excessive overlap of examination material between examinations did not exist. A total of 60 sample plans were developed: 23 sample plans for the written examinations, 25 sample plans for JPMs, and 12 sample plans for simulator examinations.

With the sample plans developed, the scope of examination material that required development was defined. The total volume of examination material that was developed included 698 written examination questions, 110 JPMs, and 48 simulator scenarios. The DOE Evaluators were responsible for the development of written examination questions and WSRC personnel were assigned to develop the JPMs and simulator scenarios.

Following initial development of the examination material, each element was reviewed by the Peer Evaluators, representatives from Operations, and DOE Evaluators prior to being submitted to DOE and WSRC management for final 
approval. The dynamic examination elements, the JPMs and simulator scenarios, were validated during the development phase to ensure accuracy of the material, to verify the adequacy of the plant procedures to support operator performance during the examination, and to verify the accuracy and objectivity of the pass/fail criteria.

As a result of the validation phase, several plant procedures were identified as being either inadequate or inaccurate. Procedural deficiencies were submitted to the procedures organization and modified procedures were developed in adequate time to support the examination process.

Examination security was maintained in accordance with WSRC policies, which required non-disclosure statements by all personnel having access to examination material, hand delivery of all hard-copy material, signature accountability of the transfer of any examination material, locked storage of examination material when not actually b.ing used, and computer security to include either password protection or locked diskettes for machines not in use.

\section{A.3 PEER EVALUATOR TRAINING}

As previously discussed, the examination process closely parallels the process used by the NRC to administer requalification examinations at commercial nuclear utilities. The examination is developed and administered by the facility, and evaluated in parallel by the NRC and the facility. To support this project at SRS, WSRC and DOE management selected a dedicated team of certified operators and supervisors to develop the necessary examination material and to administer the examinations and evaluate the results.

Peer Evaluators are Westinghouse certified supervisors. The individuals were selected based on experience, overall plant knowledge, and professional standing within the certified ranks. The Peer Evaluators normally hold supervisory positions at either the $L$ or $P$ Reactors.

The Peer Evaluators were highly proficient in plant operations but were unfamiliar with the evaluation process scheduled for $K$ Reactor. To familiarize the Peer Evaluators and the training support group on the examination requirements, a training course was developed and delivered by 
commercial industry operations and training experts during the weeks of April 23, 1990 (Phase I and II) and March 26, 1991 (Phase III). Areas covered in this course included: examination validity and reliability; the Systematic Approach to Training (SAT) methodology for development and administration of exams; the development, administration, and evaluation of Simulator, Written, and Job Performance Measures (JPM) examinations; and evaluator techniques. Practical exercises included workshops on developing JPMs and simulator sessions. The simulator sessions were evaluated by the Pear Evaluators with the DOE instructors providing feedback on questioning and evaluation techniques.

The division of responsibility within Westinghouse provided that the training support group develop examination material and the Peer Evaluators review, validate, and eventually administer the examination. The review and validation phases allowed the Peer Evaluators to increase their familiarity with the examination material and to practice evaluator techniques. Prior to the actual administration of the examinations, practice sessions were conducted by DOE and Fer Evaluators to polish evaluator techniques and to clarify roles and responsibilities. The final result was that Peer Evaluator performance was comparable to that of facility evaluators normally seen in the commercial nuclear industry.

\section{A.4 DOE EVALUATOR TRAINING}

Initial discussions between the DOE Savannah River Restart Office (SRSPO) and Pacific Horthwest Laboratory (PNL) to assist in the verification of operator readiness at SRS were held in the spring of 1989. A contract was established to provide PNL personnel who were certified NRC 1 icense examiners. Due to the scope of work envisioned, a competitive subcontract was issued to Sonalyst, Inc. to provide additional certified license examiners for the project.

To provide the DOE evaluators with training in heavy water reactor technology and an introduction to the reactors at SRS, a Savannah River Reactor Systems training course was developed and conducted by DOE at the National Emergency Training Center in Emmitsburg, Maryland from October 30 through November 4, 1989. The course of instruction included such topics as: 
SRS reactor systems, instrumentation, Technical Specifications and Technical Standards, safety analysis, heavy water reactor physics, and plant operations. Additionally, all personnel supporting the project attended Site Orientation Training at SRS. This training was conducted in January, 1990 and included: systems overview, integrated plant operations, radiological hazards and controls, site organizations and functions, and a walk-down of the $K$ Reactor facilis. To allow the opportunity for additional study, the Sonalyst and PNL home offices were provided training material developed by the Reactor Training and Prucedures (RTAP) Department. They were also supplied copies of significant operating procedures, including the Abnormal Condition Control Procedures (ACCS).

The initial on-site assignment for DOE Evaluators was the assessment of operator performance during simulator scenarios being conducted as part of the Westinghouse Management Assessment Program (MAP). The purpose of MAP was to allow Westinghouse senior management the opportunity to evaluate operator performance during simulated plant events. All MAP assessments were conducted ir the SRS simulator, located in the 707-C facility. The MAP assessments provided DOE Evaluators with the opportunity to become familiar with the Central Control Room (CCR) and the operations procedures. It also gave the evaluators the opportunity to observe the conduct of operations.

The DOE Evaluators participated in a total of fourteen assessments. In preparation for the assessments, the DOE evaluators studied the appropriate operating procedures for the planned scenarios and prepared the forms for evaluacing the performance of crews in the simulator. The evaluators conducted an independent evaluation of crew performance during the scenarios, and immediately following each simulator session, the DOE Evaluators were debriefed by the training instructors on the adequacy of operator performance. The DOE Evaluators then provided Westinghouse personnel with any additional findings observed during the session and offered any insights into methods observed within the commercial industry that would result in improved operator or instructor performance. At the completion of each assessment, a detailed report on both operator and Westinghouse instructor performance was provided to the on-site DOE sponsor. 
These training and assessment activities provided the DOE Evaluators significant opportunities to become familiar with SRS plant design, operating procedures, and conduct of operations prior to the commencement of the examination development stages for $K$ reactor. 
APPENDIX B

EXAMINATION ADMINISTRATION PHASE 


\section{APPENDIX B}

\section{EXAMINATION ADMINISTRATION}

The third and final phase of examinations conducted to formally certify $K$ reactor personnel commenced on May 23, 1991 and continued through August 2, 1991. Reexaminations of personnel who failed one or more portions of the evaluation continued until October 10, 1991. The evaluation consisted of three examinations; (a) written examination, (b) job performance measures examination and (c) simulator examination. The basis for the examinations is the "KNOWLEDGES AND ABILITIES CATALOG FOR NUCLEAR POWER PLANT OPERATORS: SAVANNAH RIVER SITE (SRS) PRODUCTION REACTORS (U)", revision 1, dated October 1, 1990. Each of these examinations will be discussed separately.

\section{B.1 WRITTEN EXAMINATION}

The written examinations administered to the operating personnel were six different 100 question examinations. A different sample plan was constructed for each examination. The sample plan identifies those important knowledge and abilities in the "KNOWLEDGE AND ABILITIES CATALOG " which are to be tested during that examination. The six sample plans for these examinations are attached as tabs B-1, B-2, B-3 and B-4 to this appendix. Each examination consisted of 100 questions conducted in two parts (a) closed book exam (66 questions) and (b) an open reference exam (34 questions). The time required to complete each portion of the examination was a maximum of 6 hours (12 hours for both portions of the examinations). The examination consisted of drawings, short answer, matching, and multiple choice questions.

The examination was administered by the WSRC Peer Evaluation group and observed by a DOE evaluator. A comment sheet was maintained by the examination proctor to document any questions asked by operators during the course of the examination. The comment sheet assists in identifying any question(s) that were ambiguous or confusing to the operators.

The written examinations were administered on the following days to the designated personnel:

May 28

$L$ and P-reactor supervisors and operators transferring to $K$ reactor.

\section{B.1}


$K$ reactor supervisors, a portion of $K$ reactor operators, and a portion of the failures from the previous exam.

August 1,2

Remainder of $K$ reactor operators and a portion of the failures from previous exams.

September 5, 6 Remainder of failures from previous examinations.

The examinations were graded separately by WSRC and the DOE evaluators. Following completion of grading, a statistical item analysis was conducted to identify questions that resulted in less than overall satisfactory performance. Additionally, all responses were reviewed for an individual having less than satisfactory performance. A11 questions were reevaluated upon completion of each examination to ensure question validity and reliability. The examination answer key was modified if any questions were determined to have more than one correct response or otherwise invalid. Once the answer key was finalized, the examinations were regraded to determine final results. Any discrepancies between Westinghouse and DOE on final results were resolved.

\section{B.2 JOB PERFORMANCE MEASURES (JPM) EXAMINATION}

A Job Performance Measure (JPM) is a specific task or procedure that has been selected as important to the safety of the plant. These tasks or procedures are reviewed and those steps that are important to the appropriate outcome of the task or directly impact plant safety are designated critical steps. In addition to completion of the task or procedure, the person being evaluated will be asked two questions about the identified task or about the system or systems directly related to the task.

The Job Performance Measure portion of the examination process was conducted using the following procedures. Each operator was required to perform ten JPM's, three of which had to be in the plant (outside of the central control room). JPM's that are conducted either in-plant or the K Reactor central control room were simulated (operators not permitted to manipulate the controls). JPM's conducted on the training simulator were usually conducted dynamically requiring the operator to take the appropriate control board operations. Tab B-5 provides the categories of tasks that were used for testing.

\section{B.2}


Because the safety significant tasks or procedures had not changed, this portion of the examination was not repeated for those personnel who had successfully passed that portion of the examination during the testing conducted in 1990.

The schedule of IPM performance is indicated below. In each case the JPM's were conducted during the normal on-shift time of the examinee. The ten JPM's were split into two days with some simulator and some field tests each day.

June 1,2 ; June 3,4 ; June 8,9 ; June 10,11 ; June 14,15

The JPM's were administered by the Westinghouse Peer Evaluators and evaluated in parallel by DOE and Peer Evaluators. A JPM was performed satisfactorily if no critical steps were performed incorrectly or omitted. Critical steps were identified during the development and validation phases of the JPM's. Upon completion of the assigned task the operator was asked the two prescripted questions by the Westinghouse evaluator and the oral answer was evaluated separately by the Peer and DOE evaluator. The weighting of the task was $75 \%$ of the JPM grade and the questions were worth $25 \%$ of the JPM grade. An operator had to obtain a weighted $80 \%$ average for all 10 JPM's to pass this portion of the examination.

\section{B.3 SIMULATOR EXAMINATION}

The simulator examination was administered to all supervisors, shift technical engineers and operators assigned to $K$ reactor for the $K$ reactor restart effort. This examination was given to five crews on successive weeks. The simulator examination followed four days of crew simulator training. The simulator examinations were conducted on the following dates:

May 23; May 30; June 6; June 13; June 21

The examination for each crew consisted of four to six individual simulator scenarios as determined by the number of operators in the crew being examined. Each simulator scenario required the crew to respond to a normal event (typically the recovery of an out of specification condition in the reactor flux distribution), an instrument and/or component failure, and a major plant transient such as a Loss of Coolant Accident or Loss of Off-site

$\bar{B} .3$ 
power. Each simulator scenario was approximately one hour in length. Tab B-6 contains examples of the various components of a scenario.

Prior to the initial simulator session, the crew was briefed on examination guidelines as specified in the Peer Evaluation Standard and crew assignments were distributed. The crew is normally ten individuals with five of the crew members assigned to the simulator for the scenario and the rest in standby to offer additional assistance during major plant transients. The crew consisted of the following:

Supervisors

Central Control Room Supervisor

Shift Test Engineer

Shift Supervisor (in standby)

\section{Operators}

Graphic Panel Operator

Console Operator

Data Operator

Relief Operator (in standby)

Both DOE and Westinghouse evaluators were present in the simulator during the scenario. Each organization had established monitoring assignments for each scenario. The lead DOE and Westinghouse evaluators concurred in the decisions concerning when to transition to the next simulator event and when to terminate the scenario session. Following completion of the scenario, the evaluators asked any followup questions of the operator they were evaluating in order to clarify any actions observed during the scenario. Boin the Westinghouse and DOE evaluators were present for any followup questioning.

Following completion of the followup questioning, the crew was released to their classroom. The two evaluation teams then met separately to review the previous scenario to identify the Individual Simulator Critical Tasks (ISCTs) that were performed and to assign individual responsibility for ISCTS that were successfully or not successfully performed. An ISCT is a task which, if omitted or incorrectly performed by an operator, will result in adverse consequence(s) which significantly alter the event mitigation strategy to the detriment of plant or public safety. Each ISCT must have plant or public safety significance, must provide the operator responsible for completing the task with appropriate cues, must have measurable performance indicators and must give the operator feedback regarding the effect of his/her action or inaction. ISCTs for each simulator scenario were preestablished during the validation phase. It was the responsibility of each evaluation team to review, at the end of each scenario, the ISCTs performed to ensure 
they still met the definition, identify any additional ISCTs that were performed, and assign individual responsibility for performance of an ISCT. The Peer Evaluation Standard required that each individual on a crew must perfo $n$ a minimum of one ISCT for the simulator examination to be considered valid.

Simulator scenarios were conducted, with rotation of crew personnel, until all requirements of the Peer Evaluation Standard for administration of a valid and reliable simulator examination were met. At this point, the crew was released and the evaluation teams caucused separately to arrive at overall simulator examination results. Each evaluation team arrived at the following pass/fail decisions:

- Individual performance based on ISCTs

- Crew performance based on ISCTs. If an ISCT was such that the crew had the opportunity to correct an individual's unsuccessful performance and mitigate an event, the ISCT was additionally considered a "crew" ISCT. The failure of a crew on two or more "crew" ISCTs required an overall crew failure.

- Individual performance based on individual competencies. The competencies reflect the major knowledge and ability requirements of the crew. The competencies are:

- Understanding/Interpretation of Annunciator/Alarm Signals

- Diagnosis of Event/Conditions based on Signals/Readings

- Compliance/Use of Procedures and Technical Specifications

- Control Board Operations

- Communications/Crew Interactions, and

- Understanding of Plant/System Response.

Each competency is sectionalized into three or four rating factors, each of which has performance indicators to ensure evaluators assign consistent grades. The pass/fail criteria for crew and individual competencies is specified in the Peer Evaluator Standard. 
Following completion of the simulator evaluation phase, the evaluation teams conducted a debrief to compare final results and supporting basis. Any discrepancies in results were identified and analyzed to ascertain the basis for the discrepancy. 


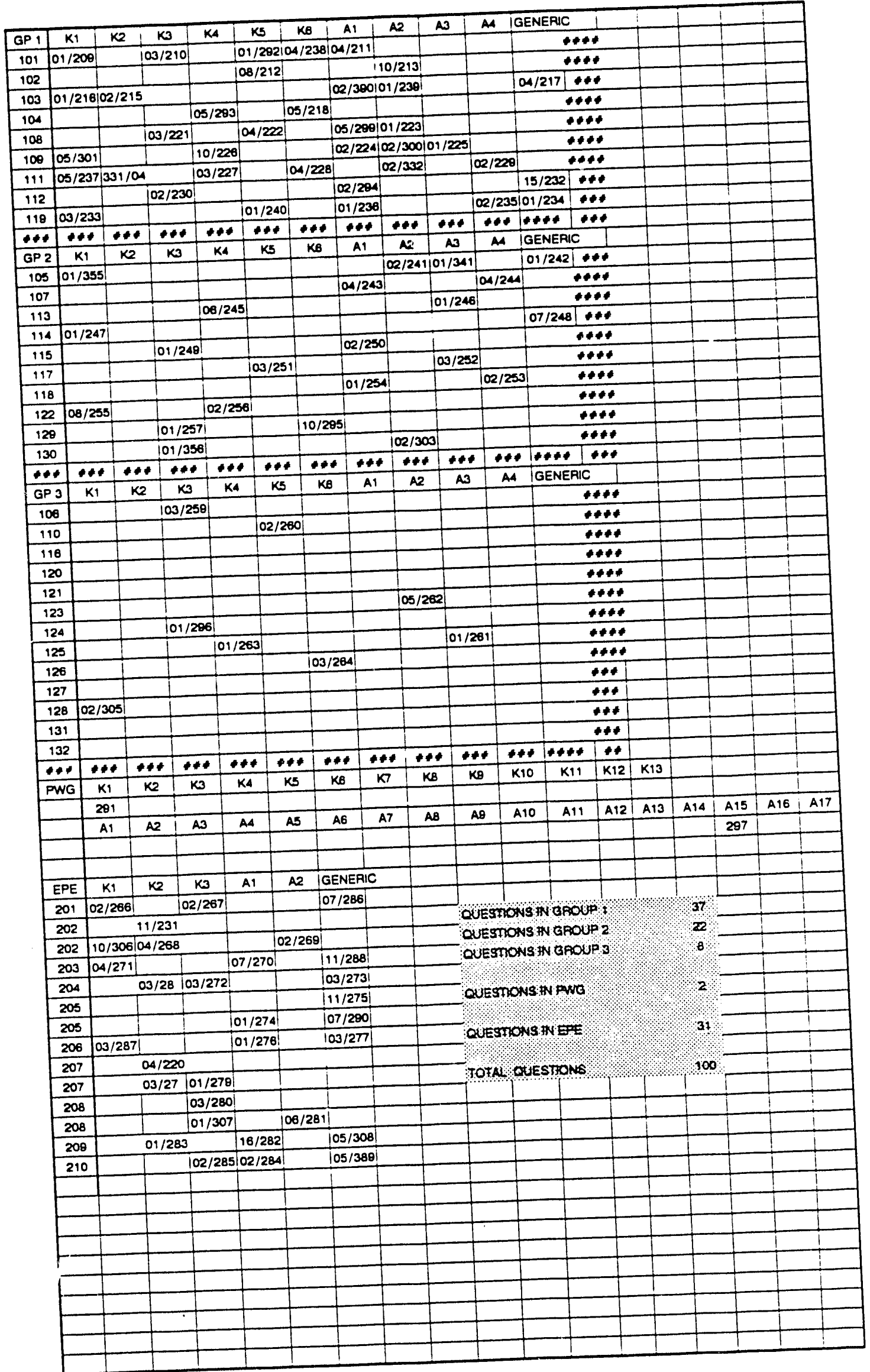




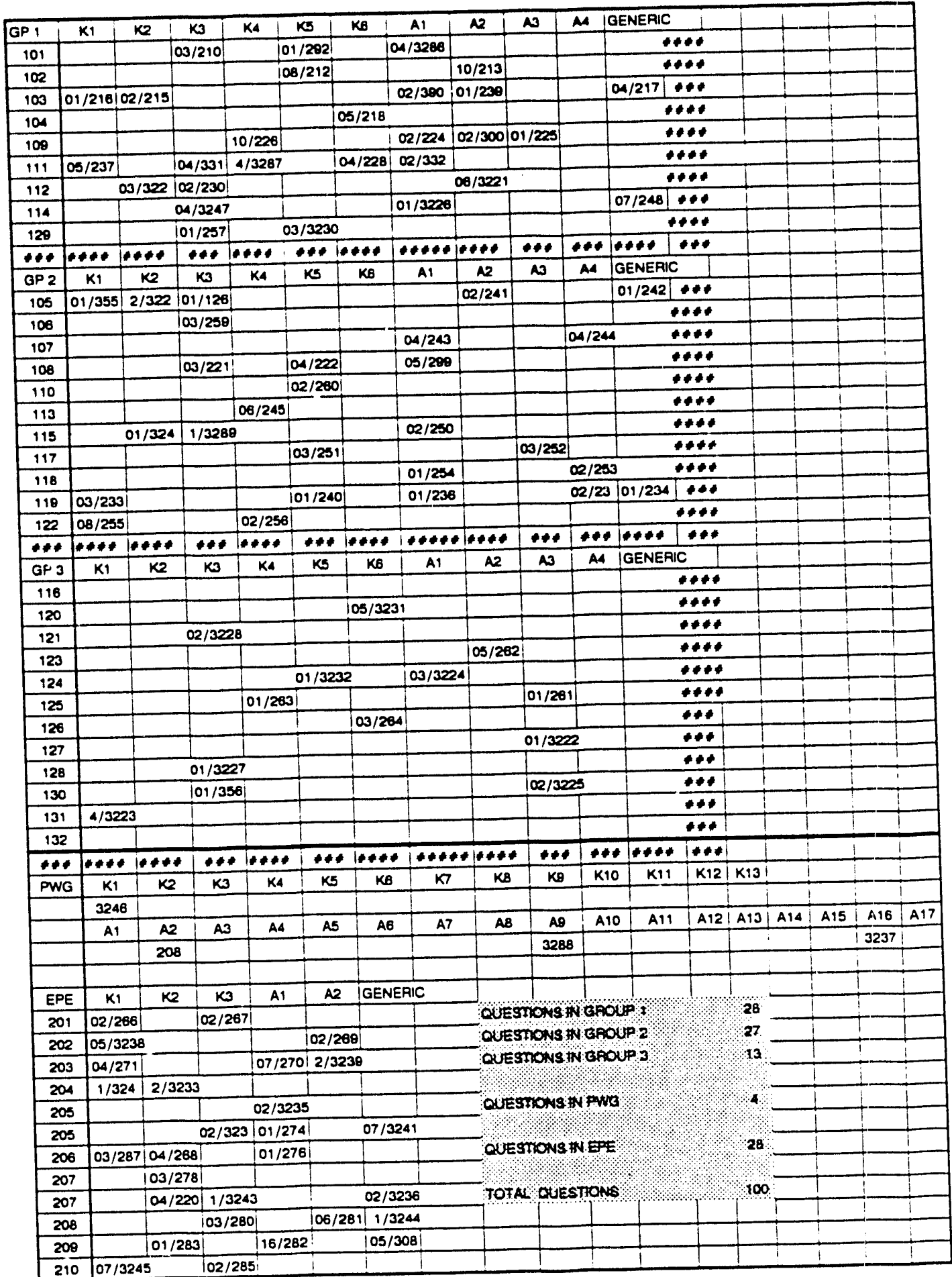


TAB 8-2: K AREA CCAS SAMPLE PLAN tor July ith and 18th

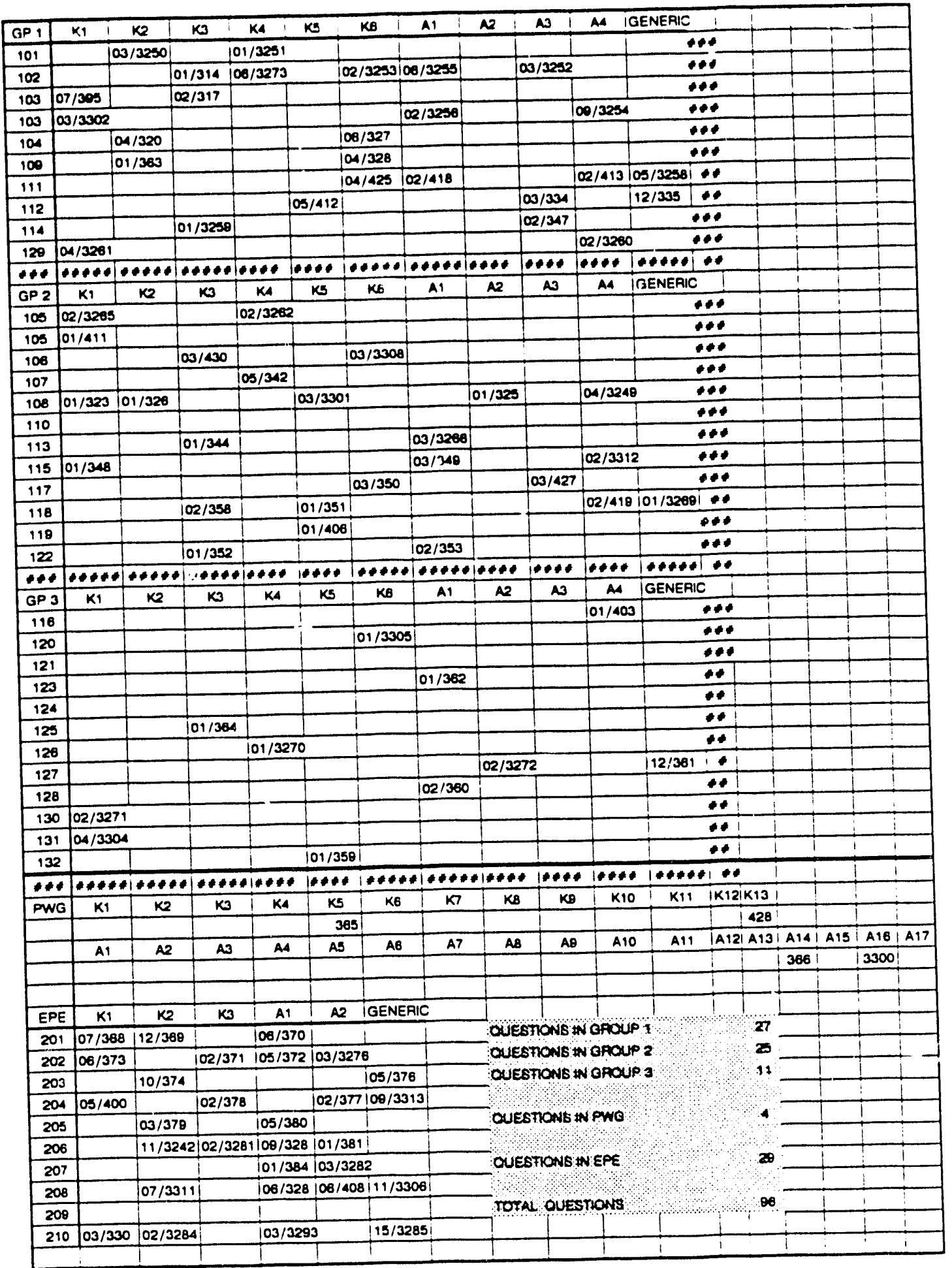




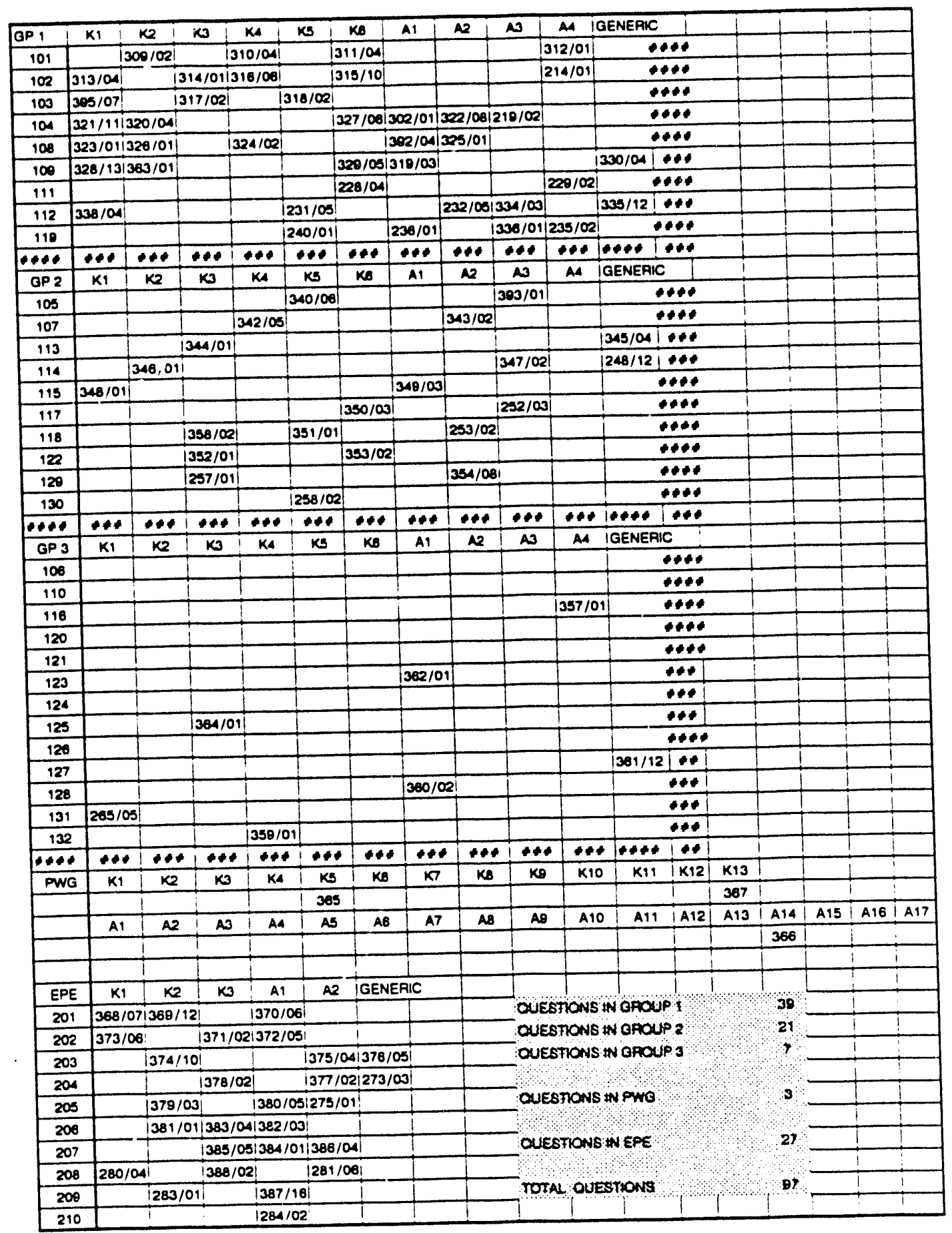




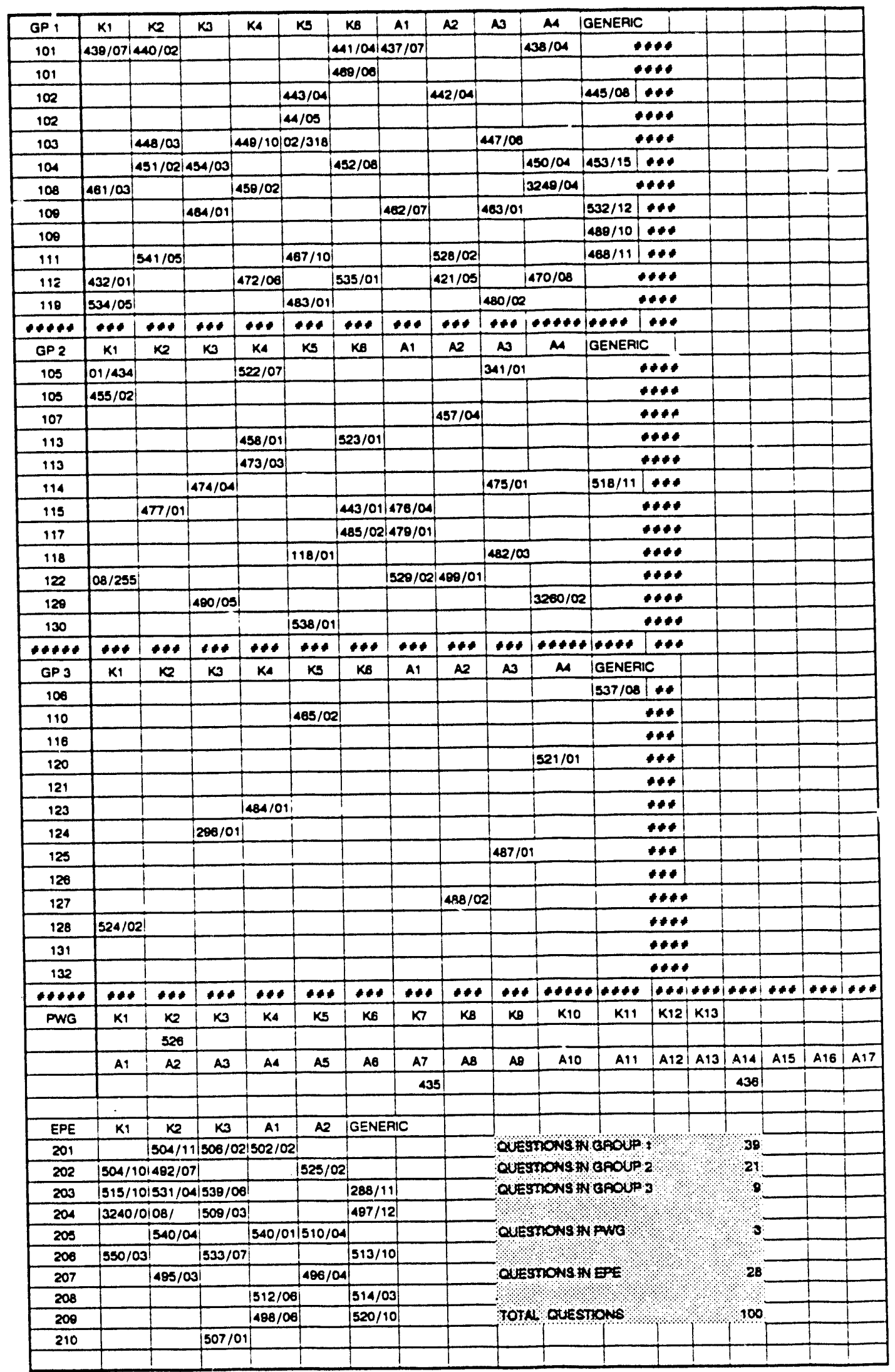




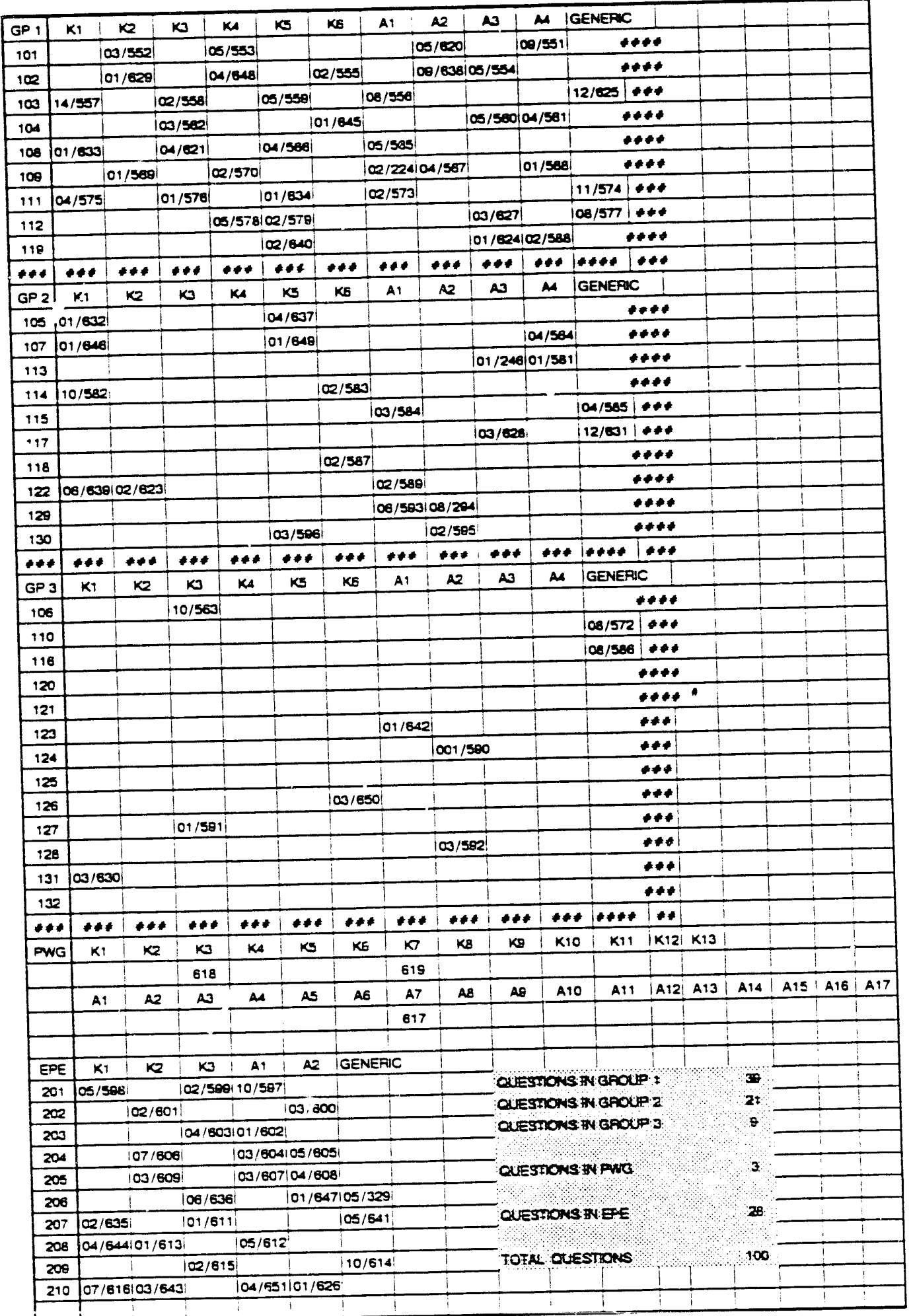


TAB-5

JOB PERFORMANCE MEASURES

\section{TESTING GROUPS}

Field Job Performance Measures - Three of twelve JPMs were selected for each operator from this category. Examples of these procedures that are conducted in $K$ reactor area outside the control room are as follows:

- Manual Start of the Booster Pump Diesel

- Emergency Spray Water Operations

- Reducing SSS Stowage Tank Pressure

- Transfer of the CW Pump Power Supply from the DG to Normal

- Manual Start of Emergency Diesel GM-1

Control Room Job Performance Measures - One of eight JPMs were selected to be performed by the operator. Examples of the system procedures conducted in the $K$ reactor control room are as follows:

- Reactor Scram, Septifoil Supply Header Pressure Very Low

- CHR Leakage into Sump

- Respond to a NIM Alarm

D20 loss rate calculation - Each operator was required to perform a D20 loss rate calculation. The calculation could be based on data from STM (stack tritium monitor) or BTM (Berthold tritium monitor) and could be at various sample points in the system.

Technical Limit Calculation - Each operator was reliuired to demonstrate the ability to manually calculate a verification of an operating limit. For example it could be a verification of a containment protection limit or a transient protection ?imit. 
Reactor Control, Reactivity - Each operator was required to demonstrate the ability to control the reactor in a dynamic simulator. For example an operator would be required to correct a Roof Top Ratio (RTR) problem or a tilt problem on the simulator.

Electrical Power Loss - Each operator was required to demonstrate the ability to respond to a major electrical power loss. Examples are responding to a loss of site power with GM\# 1 requiring a manual start.

Emergency Actions (Memorized Portions) - Each operator was required to execute the immediate actions for a Reactor Incident, MC-2 or a Reactor Emergency, MC3. The required conditions were presented by the dynamic simulator requiring the operator to assimilate the conditions and take the appropriate, required actions.

Accident Casualty Control Procedures - One of six JPM's was selected from this category. Examples that were required to be conducted on a dynamic simulator are as follows:

- Plenum Pressures Down 10\%, PW-305

- Moderator Recovery System Operation, MC-20

- A/C Motor Failure, PW-300 
TAB-6

\section{SIMULATOR SCENARIO EVENTS}

Major Incident - Each scenario would contain one event from this group.

Examples of these events are as follows:

- Loss of Coolant Accident

- Loss of Offsite Electrical Power

- Anticipated Transit Without Scram (ATWS)

- Major Cooling Water Leak

Component Failure - Each scenario would contain one event from this group. Examples of these events are as follows:

- Four Safety Rods Fail to Scram

- GM Diesels Fail to Start

- Accident-Incident Switch Failure

- Process Water A/C Motor Failure

Instrument Failure - Each scenario would contain one event from this group. Examples of these events are as follows:

- Control Rod Drive Out

- Safety Computer

- Cooling Water Scram Circuit

- Blanket Gas Blower

Normal Event - Each scenario would contain a normal operating event that would involve reactivity addition on an operating reactor. Examples of these events are as follows:

- Correct Out of Specification Rooftop Ratio (RTR)

- Correct Tilt Ratio

- Set Partial Control Rods

- Obtain Required Reactor Engineerir.g Data 
TAB-7

SYSTEM AND EMERGENCY PLANT EVOLUTION TITLES

101

102

103

Reactor Scram System (SCRM)

Supplementary Safety System (SSS)

Emergency Cooling System (ECS)

Airborne Activity Confinement System (AACS)

Emergency Electrical Power (EEP)

Compressed Air System (CAS)

Process Room Spray System (PRS)

Confinement Heat Removal System (CHR)

Process Water System (PWS)

Process Water Diesel Generator (PWDG)

Control and Safety Rod System (CRD)

Cooling Water System (CW)

Contaminated Water Removal and Disposal System (CWRD)

Safety Related AC Circuits (AC)

Moderator Recovery System (MRS)

PW Pump and Motor Lubrication 0i1 System (PWLO)

Electric Load Shedding (LS)

Stack Air Activity Monitoring (SAAM)

Building Radiation Monitoring (BRM)

Safety Related 125 VDC Power (SRDC)

nischarged Assembly Cooling (DAC)

Blanket Gas System (BG)

Cooling Water Gamma Monitoring (CWGM)

CCR Habitability System (CCRH)

Essential Equipment Monitoring (EEM)

Reactor Effluent Water Monitoring (REWM)

Reactor Tank Pressure Relief System (RPR)

River Water and PAR Pond Pumps and Valves (RWPV)

Disassembly Basin and Disassembly Basin

Cooling and Filtration System (DB/DBCF)

Reactor Building

Reactor Tank Internals and Supports (RTIS)

Domestic and Fire Protection Water (DFW)

SCRAM Condition Present and Reactor Power

Above HLFM Downscale or Unknown (ATWS)

Inadvertent Reactivity Addition

Fuel Failure

Partial or Complete Loss of Forced Core Flow Circulation

Loss of Blanket Gas

Reactor Tank Low Water Level

High Offsite Release Rate

Charge/Discharge Event

Control Room Abandonment

Partial or Complete Loss of AC Power 
PNL-7871

UC -731

\section{DISTRIBUTION}

No. of

Copies

\section{OFFSITE}

12 DOE/Office of Scientific and Technical Information

3 F. R. McCoy

SR Restart

U.S. Department of Energy

Box A

Aiken, SC 29808

R. Schepens

Director, Reactor Operations and Training Division, SRS-PO

U.S. Department of Energy

Box A

Aiken, SC 29808

C. A. Everatt

Deputy Director, Reactor Operations and Training Division, SRS-PO

U.S. Department of Energy

Box A

Aiken, SC 29808

2 S. D. Richardson

Deputy Assistant Secretary for Facilities, DP-60

U.S. Department of Energy 1000 Independence Ave. SW

Washington, D.C. 20585

M. Haughey

Acting Director, Savannah River

Restart Office, EH-41

U.S. Department of Energy

1000 Independence Ave. SW

Washington, D.C. 20585
No. of

Copies

F. Kimball

Savannah River Restart Office, EH-41

U.S. Department of Energy

1000 Independence Ave. SW

Washington, D.C. 20585

P. Wu

Office of Nuclear Safety, NS-10

U.S. Department of Energy

19901 Germantown Road

Germantown, MD 20545

C. J. Carrol

Sonalyst, Inc.

Box 280

Waterford, CT 06385

\section{ONSITE}

DOE Field Office, Richland

D. C. Langstaff

$(A 5-90)$

13 Pacific Northwest Laboratory

L. R. Dodd

D. G. Draper

R. L. Grue1

S. W. Heaberl in

R. L. Moffitt

M. P. Morgan

B. D. Shipp

Publ ishing Coordination

Technical Report Files

$(\mathrm{K} 6-48)$

$(K 6-46)$

$(K 6-46)$

$(K 6-42)$

$(K 6-46)$

$(K 6-46)$

$(K 1-73)$

(5) 

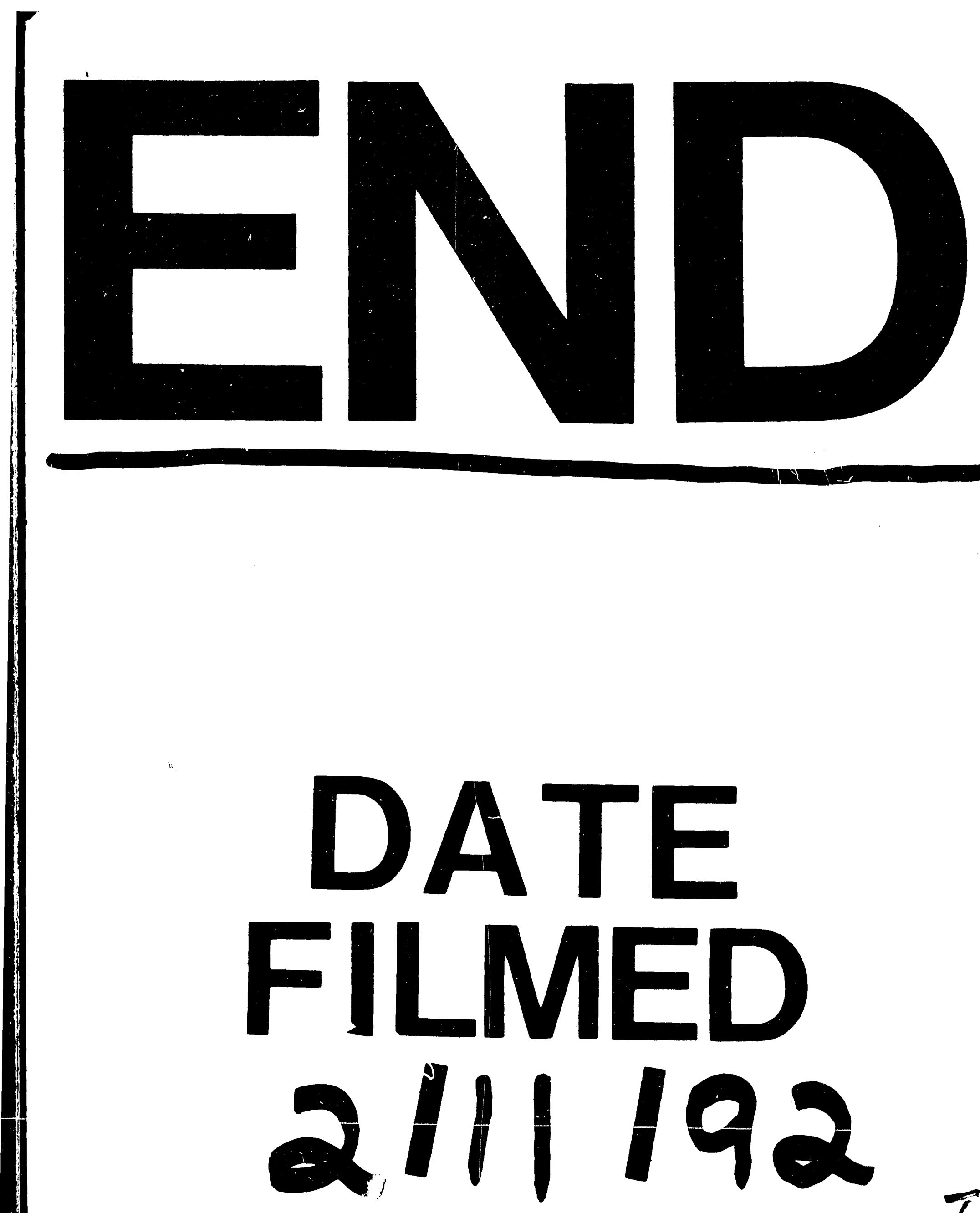

$I$ 
